\title{
LAS EMERGENCIAS CONSTITUCIONALES NO REGLADAS O INSUFICIENTEMENTE REGLADAS: UNA APROXIMACIÓN TEÓRICO-PRÁCTICA*
}

\author{
PABLO FERNÁNDEZ DE CASADEVANTE MAYORDOMO \\ Profesor Titular $(A)$ de Derecho Constitucional \\ Universidad Rey Juan Carlos
}

TRC, n. ${ }^{\circ} 48,2021$, pp. 495-524

ISSN 1139-5583

\section{SUMARIO}

I. Introducción. II. Las emergencias constitucionales no regladas o insuficientemente regladas: parámetros jurídicos de actuación. III. A vueltas con la insuficiencia previsora del artículo 116 CE y de la LOEAES ante ciertas crisis sobrevenidas. IV. Conclusiones.

\section{INTRODUCCIÓN}

Partiendo del estado de normalidad ${ }^{1}$ jurídica bajo el que suelen discurrir los sistemas constitucionales contemporáneos, la realidad nos demuestra cómo, en ocasiones, la comunidad política experimenta alteraciones cuya magnitud puede incluso poner en peligro la pervivencia misma del sistema ${ }^{2}$. Y, es que, dejando a un lado el supuesto extremo de las contiendas bélicas, no es extraño que las democracias actuales acaben teniendo que hacer frente a ciertos peligros frente a los que no siempre se encuentran normativamente pertrechadas, lo cual genera importantes problemas a la hora de conjugar seguridad jurídica con eficacia en la respuesta frente a la emergencia.

* Este artículo se encuentra vinculado al proyecto de investigación con referencia DER2016-76312-P.

1 Para De Esteban, J. y GonzÁlez-Trevijano, P., Tratado de Derecho Constitucional. Tomo II, Madrid, UCM, 2. ${ }^{a}$ ed., 2004, p. 469, la naturaleza del Estado de Derecho «se basa (...) en tres presupuestos delimitadores: normatividad, generalidad y normalidad».

2 Pérez Serrano, N., Tratado de Derecho Político, 2. ${ }^{\text {a }}$ edición, Civitas, Madrid, 1984, p. 418. 
Que esto es así queda evidenciado, por ejemplo, en el marco de la lucha global contra el terrorismo islamista, con unas democracias occidentales obligadas a adaptar sus ordenamientos nacionales para imponer medidas extraordinariamente invasivas en lo que a los derechos fundamentales se refiere. También con la amenaza que, para la continuidad del sistema, supone el auge de los nacionalismos y la consiguiente proliferación de iniciativas aislacionistas o separatistas, cuyo objetivo último suele ser la subversión del orden constitucional establecido. Con el drama de las crisis migratorias a gran escala, frente a las que los Estados responden con la imposición de medidas que, en ocasiones, suponen el incumplimiento de su legislación interna y de los compromisos adquiridos en el ámbito del derecho internacional humanitario. $\mathrm{O}$, por descontado, con la crisis sanitaria generada a raíz de la pandemia por COVID-19, con un recorte general de derechos y libertades que, no encontrando paragón en nuestra historia moderna, ha tenido lugar, en ocasiones, al margen de las reglas preestablecidas.

Estos y otros ejemplos ilustran a la perfección el estado de permanente vigilancia en que deben vivir los ordenamientos constitucionales ante sus más directas amenazas, dispuestas a aprovechar cualquier síntoma de debilidad para erosionar y, en última instancia, destruir el sistema constitucional, «única forma posible de la democracia, como la teoría y la práctica han demostrado» ${ }^{3}$. Porque, aunque esos peligros, si se afrontan adecuadamente, no tienen en principio capacidad para acabar por sí solos con el orden vigente, sí pueden ser aprovechados por la autoridad pública para imponer medidas que paulatinamente vayan minando el sistema ${ }^{4}$. Y, si ese peligro se hace patente cuando se aplica normativa previamente positivada, aún más visible será en los casos en los que la emergencia surgida exceda el campo de lo previamente regulado y se adentre en territorio jurídicamente desconocido.

Siendo precisamente esa última la cuestión que centra la atención de este trabajo, de lo que estamos hablando es de establecer los cortafuegos suficientes para impedir el aprovechamiento de las crisis para debilitar y, en última instancia, destruir el sistema de libertades vigente. De articular las garantías necesarias frente a las tentaciones de ejercer un poder pleno e incontrolado porque, por paradójico que pueda parecer, incluso cuando el peligro inicial proceda del exterior, su más firme aliado puede encontrarse dentro del propio entramado institucional, y ante eso también hay que estar preparado.

3 Aragón Reyes, M., «La crisis de la democracia constitucional: ¿un pasado que amenaza volver?», Revista de Libros, Segunda Época, 2019, p. 10, en el marco de la recensión a De Miguel Bárcena, J. y TAJAdura Tejada, J., Kelsen versus Schmitt. Política y derecho en la crisis del constitucionalismo, Guillermo Escolar, Madrid, 2018.

4 Loewenstein, K., Teoría de la Constitución, Barcelona, Ariel, 2. a edición (4. ${ }^{\text {a }}$ reimpresión), 1986, p. 286. La obra original vio la luz en 1957, con el título de Political Power and the Governmental Process (University of Chicago Press). Y en cuanto a la edición alemana, se publicó en 1959, con el título de Verfassungslehre, J. C. Mohr (Paul Siebeck), Tübingen. 
Sentada, por tanto, la vulnerabilidad de toda democracia y la necesidad de que adopte una actitud de permanente alerta, lo siguiente es tratar de articular el modelo más eficaz posible frente a las emergencias constitucionales, sin que ello suponga renunciar, al mismo tiempo, al establecimiento de unas garantías suficientes que impidan la concentración exacerbada de poderes en un único centro o magistratura.

Toca, por lo tanto, preguntarse por el modelo ideal de respuesta frente al hecho jurídico-político extraordinario, teniendo siempre presente que, pese a los esfuerzos que puedan realizarse de cara a la previsión normativa de la excepción, esta es impredecible por naturaleza ${ }^{5}$. Pues bien, lejos de tratarse de una cuestión pacífica, el análisis comparado de la cuestión revela una importante heterogeneidad por parte de los sistemas constitucionales a la hora de enfocar el problema. Y, es que, mientras unos optan por la no constitucionalización previa de situaciones de crisis, otros deciden incluir ciertas reglas jurídicas, conscientes en cualquier caso de esa imposibilidad de anticipar plenamente todas y cada una de las situaciones de emergencia susceptibles de producirse a lo largo de la vida del Estado.

Respecto a lo anterior, y sobre la base de lo dicho en otro momento ${ }^{6}$, recuérdese a grandes rasgos como, los Estados que optan por la no constitucionalización previa de la amenaza, han solido fiar la respuesta a la aplicación del derecho de necesidad ${ }^{7}$. En cambio, los sistemas que deciden constitucionalizar la emergencia lo hacen, bien a través del establecimiento de cláusulas generales - también conocidas como dictadura constitucional ${ }^{8}$ o comisarial ${ }^{9}$ - , como el caso del artículo 16 de la Constitución francesa de 1958, o bien mediante la previsión detallada de uno o más supuestos excepcionales — por ejemplo, los estados de alarma, excepción y sitio del artículo $116 \mathrm{CE}$ -

Y ello teniendo en cuenta, al mismo tiempo, que independientemente de cuál sea la opción finalmente plasmada en un texto constitucional concreto, hace ya tiempo que el legislador ha asumido, en la generalidad de los casos, una labor

5 Siguiendo a Schmiтt, C., Politische Theologie: vier Kapitel zur Lebre von der Souveranität, München, Duncker und Humblot, 2004, pp. 13 y 14, «el caso excepcional, el que no está previsto en el ordenamiento jurídico vigente, puede como mucho ser calificado como caso de extrema necesidad, de peligro para la existencia del Estado o de otra forma análoga, pero no se puede delimitar rigurosamente».

6 Fernández de Casadevante Mayordomo, P., «El derecho de emergencia constitucional en España: hacia una nueva taxonomía», RDP, n. ${ }^{\circ} 107,2020$, pp. 115 a 118.

7 Notrecht en alemán, según terminología empleada por Loewenstein, K., Teoría de la Constitución, op. cit., p. 286. En esa línea, pero aludiendo a la «fuerza mayor», WigNy, P., Droit Constitucionnel, Établissements Émile Bruylant, Bruxelles, 1952, pp. 198-200.

8 Friedrich, C. J., Gobierno constitucional y democracia, Instituto de Estudios Políticos, Madrid, 1975, sobre todo, desde la p. 585. Posteriormente, por ejemplo, Loewenstein, K., Teoría de la Constitución, op. cit., p. 289. Sobre el origen romano de la institución y los requisitos que, a su juicio, deben observarse para calificar una dictadura como constitucional, Rossiter, C. L., Constitutional Dictatorship: Crisis Government in the Modern Democracies, Princeton University Press, Princeton, NJ, 1948, pp. 3-5 y 298-306.

9 Sснмітт, C., Die Diktatur, Achte, korrigierte Auflage, Duncker \& Humblot, Berlin, 2015. La primera edición vio la luz en el año 1921. 
de regulación de la emergencia constitucional más propia del poder constituyente - $\mathrm{O}$ del constituyente constituido, si hablamos de reforma constitucional-, lo que implica, «en cierto modo, un cambio permanente en el sistema constitucional de derechos y procedimientos» ${ }^{10}$.

En efecto, y al margen de las extraordinarias limitaciones aprobadas por vía legislativa tras los atentados terroristas perpetrados en Estados Unidos, el 11 de septiembre de $2001^{11}$, el fenómeno de la «desconstitucionalización» de medidas extraordinarias se ha vuelto a hacer especialmente visible con motivo de la crisis sanitaria provocada por la COVID-19. En concreto, y en atención al Informe Provisional elaborado por la Comisión de Venecia a encargo de la Unión Europea - octubre de 2020—, comprobamos que solo Bulgaria, España, Estonia, Finlandia, Hungría, Luxemburgo, Portugal, República Checa y Rumanía habían optado hasta el momento por la declaración de estados de emergencia constitucionalmente previstos. El resto, en cambio, se decantó, bien por activarlos en aplicación de legislación ordinaria — Alemania, Eslovaquia, Francia, Italia y Letonia—, o bien por no emplear regulación extraordinaria de iure, recurriendo en la mayoría de casos a la legislación sanitaria y, al mismo tiempo, a medidas especiales para afrontar la crisis - Austria, Bélgica, Chipre, Croacia, Dinamarca, Eslovenia, Grecia, Irlanda, Lituania, Malta, Países Bajos, Polonia, Suecia y Reino Unido- ${ }^{12}$.

En cualquier caso, sea cual sea el sistema concreto que cada país escoja, y al margen de los problemas teóricos que plantea dar por buena la regulación al margen de la Constitución ${ }^{13}$, hay una idea común que debe destacarse en todos los casos y sobre cualquier otra consideración. Y, es que, ante las situaciones de crisis, no todo vale y, por elevada que pueda ser la magnitud de la amenaza, el ordenamiento jurídico no llega nunca a suspenderse totalmente.

$\mathrm{Al}$ análisis de esta última cuestión dedicamos el siguiente apartado, no sin antes puntualizar que nada impide la simultánea aplicación de regulación previa y de derecho de necesidad, ello para los casos en los que la amenaza no estuviera suficientemente reglada ${ }^{14}$. De lo contrario, se estaría aceptando la indefensión y

10 Ferejohn, J. y PAsquino, P., «The law of the exception: a typology of emergency powers», International Journal of Constitucional Law, vol. 2, Issue 2, 2004, p. 233.

11 Vid. Álvarez Conde, E. y González, H., «Legislación antiterrorista comparada después de los atentados del 11 de septiembre y su incidencia en el ejercicio de los derechos fundamentales», Análisis del Real Instituto Elcano (ARI), n. ${ }^{\circ}$ 7, 2006, pp. 4 y ss.

12 CDL-AD (2020)018, Informe Provisional sobre las medidas adoptadas en los Estados miembros de la UE como resultado de la crisis del COVID-19 y su impacto en la democracia, el Estado de derecho y los derechos fundamentales (8-9 de octubre de 2020), pp. 9 y ss.

13 Ello referido, claro está, a los sistemas estatales vinculados a los principios de supremacía y supralegalidad constitucional. Al respecto, Aragón ReYes, M., «Sobre las nociones de supremacía y supralegalidad constitucional», REP, n. ${ }^{\circ}$ 50, 1986, pp. 9-30.

14 En contra, Serrano Alberca, J. M., «Artículo 116», Garrido Falla, F. (dir.), Comentarios a la Constitución, Madrid, Civitas, 1985, pp. 1771 y ss.; o Carro Martínez, A., «Artículo 116 CE: situaciones de anormalidad constitucional», Alzaga Villaamil, Ó. (dir.), Comentarios a la Constitución Española de 1978, 
derrota del Estado de derecho cuando la normativa de emergencia constitucional previamente existente fuera insuficiente para revertir la situación de crisis surgida.

\section{LAS EMERGENCIAS CONSTITUCIONALES NO REGLADAS O INSUFICIENTEMENTE REGLADAS: PARÁMETROS JURÍDICOS DE ACTUACIÓN}

$\mathrm{Si}$, como decíamos, todo Estado de derecho, en cuanto que «Estado sujeto a normas» ${ }^{15}$, se basa en la aplicación habitual y general de una serie de reglas jurídicas preestablecidas, las situaciones de emergencia constitucional suponen la activación de un régimen jurídico sustancialmente distinto y, en ocasiones, ni siquiera anticipado normativamente o, al menos, no en su totalidad.

Es así como distinguimos entre las emergencias constitucionales regladas y las que no lo están - ya sea total o parcialmente-, categorías propias de lo que para nosotros es el derecho de emergencia constitucional. Remitiéndonos a otro trabajo previo de cara a conocer cuáles son los elementos que conforman la vertiente reglada ${ }^{16}$, cuestión mucho menos problemática, analizamos aquí qué sucede cuando el ordenamiento vigente en el momento de la crisis resulta insuficiente para afrontar con garantías y eficacia la situación surgida. A tal cometido nos dedicamos desde ahora, volviendo a recordar para ello que, incluso ante las amenazas no reguladas previamente, la «suspensión total del ordenamiento jurídico vigente ${ }^{17}$ nunca puede ser una opción.

En efecto, a pesar de la entidad de las medidas adoptadas en tiempos de anormalidad constitucional, muchas de las cuales suelen implicar la suspensión en materia de derechos fundamentales, lo cierto es que, si se actúa adecuadamente, el derecho subsiste en todo caso. En realidad, lo que sucede es que las reglas jurídicas ordinarias, previstas para situaciones igualmente comunes, pasan a un segundo plano, ello en favor de otras de tipo extraordinario pero no por ello menos constitucionales. Sobre todo si tenemos en cuenta que muchas de ellas suelen estar contempladas en la propia Carta Magna o en la legislación de desarrollo, sujeta por definición al control de constitucionalidad ${ }^{18}$. Y respecto a los

Tomo IX, Edersa, Madrid, 1998, p. 254, cuando niega la posibilidad de suspender otros derechos que no sean los citados por el artículo $55 \mathrm{CE}$, «por muy enrarecida y dificultosa que sea la emergencia surgida».

15 De Esteban, J. y González-Trevijano, P., Tratado de Derecho Constitucional. Tomo II, op. cit. , p. 469.

16 Fernández de Casadevante Mayordomo, P., «El derecho de emergencia constitucional en España: hacia una nueva taxonomía», op. cit., pp. 124 a 126.

17 Como sí defiende Schmiтt, C., Politische Theologie: vier Kapitel zur Lehre von der Souveranität, op. cit., pp. 18 y ss., añadiendo poco después que, «ante un caso excepcional, el Estado suspende el Derecho en virtud del derecho a su propia conservación».

18 En igual dirección, Pérez Serrano, N., Tratado de Derecho Político, op. cit., p. 479; De Esteban, J., y González-Trevijano, P., Tratado de Derecho Constitucional. Tomo II, op. cit., p. 415. En contra, De VergoTTINI, G., Derecho Constitucional Comparado, Espasa Calpe, Madrid, 1983, pp. 190 y 191; y Goig MarTínEZ, J. 
peligros no regulados $-\mathrm{O}$, al menos, no lo suficientemente-, la conclusión no difiere en lo esencial pues, incluso ahí, la solución dispensada se encuentra condicionada al respeto de una serie de parámetros jurídicos que, como es lógico, pueden devenir más difusos que si de amenazas perfectamente regladas se tratara.

De hecho, es en la insuficiencia regulatoria donde, para nosotros, se manifiesta el auténtico derecho constitucional de excepción ${ }^{19}$, en contra de lo afirmado por la doctrina general española, que acostumbra a circunscribir dicho concepto — también el de estado de excepción, entendido en sentido amplio_-, a la aplicación de regulación previamente existente —artículo $116 \mathrm{CE}$ al frente — ${ }^{20}$. Porque la verdadera excepción jurídico-política aparece ante supuestos que, por su inverosimilitud, logran escapar al afán regulatorio previo del poder constituyente y del legislador ${ }^{21}$. Son situaciones en las que el estado de necesidad hace acto de presencia, concediendo a la autoridad un margen inusitado de cara a la imposición de las medidas anticrisis.

Pero, conviene insistir, ello no significa la plena libertad para la adopción de cualesquiera medidas. Y, es que, en contra de la tesis derogatoria defendida por Schmitt ${ }^{22}$, la opción del poder constituyente por la democracia implica, incluso en tiempos de anormalidad constitucional, el matrimonio indisoluble con una serie de reglas, principios y/o valores jurídicos sin los cuales aquella dejaría de existir ${ }^{23}$.

Sentado lo cual, lo siguiente es tratar de identificar esos elementos jurídicos que subsisten incluso ante las situaciones más extremas de amenaza al orden constitucional y que, como veremos, actúan a modo de garantía o contrapeso frente a los poderes excepcionales adquiridos por las autoridades públicas.

M., «Defensa política de la Constitución. Emergencia, excepcionalidad y democracia», Cuestiones Jurídicas, vol. VIII, n. ${ }^{\circ} 2,2014$, p. 14.

19 Como ya tuvimos ocasión de defender en Fernández de Casadevante Mayordomo, P., «El derecho de emergencia constitucional en España: hacia una nueva taxonomía», op. cit., pp. 111-145.

20 A destacar, Cruz Villalón, P., Estados excepcionales y suspensión de garantías, Tecnos, Madrid, 1984, p. 31, por ejemplo, al afirmar que «el presupuesto esencial del estado excepcional es la tipificación de la emergencia»; y FERNÁNDEZ SEGADO, F., «La suspensión de garantías constitucionales en la nueva Constitución española», REP, n. ${ }^{\circ} 7,1979$, pp. 310 y 311, cuando se refiere a las situaciones del artículo 116 CE como aquellas que «dan lugar a cualquiera de los estados excepcionales». O el propio Tribunal Constitucional, en su STC $83 / 2016$, de 28 de abril, FFJJ 7 y 10.

21 Coincidimos pues con Schmiтt, C., Politische Theologie: vier Kapitel zur Lehre von der Souveranität, op. cit., pp. 13 y 14, cuando define el «caso excepcional» como «el que no se encuentra previsto en el ordenamiento jurídico vigente».

22 Schmitт, C., Teoría de la Constitución, Alianza Editorial, Madrid, 2011, pp. 58 y ss., y la distinción que realiza entre lo que para él es la Constitución en sentido positivo y su vertiente relativa.

23 En este sentido, Torres del Moral, A., «Prólogo», Partidos Políticos y Constitución: un estudio de la LO 6/2002, de 27 de junio, de Partidos Políticos y de la STC 48/2003, de 12 de marzo, Civitas, Madrid, 2004, p. 25; López Guerra, L., Introducción al Derecho Constitucional, Tirant lo Blanch, Valencia, 1994, p. 31; o Lucas Verdú, P., Curso de Derecho Político, vol. IV, Tecnos, Madrid, 1984, pp. 363 y ss. Es ello lo que nos ha llevado a defender en otros trabajos el carácter militante o combativo de la democracia española, ello a pesar de la no existencia de límites expresos a la reforma constitucional. Vid. FERnÁndez DE CASAdevante MAYORDOMO, P., ¿Son admisibles todos los proyectos en democracia? La izquierda nacionalista radical vasca: de su ilegalización a un discutible regreso a las instituciones públicas, Tirant lo Blanch, Valencia, 2019, pp. 25 a 39. 


\section{A nivel interno}

Comenzando por las referencias jurídicas internas, es la propia Constitución la que explicita una serie de reglas, principios y/o valores ${ }^{24}$ inherentes al sistema jurídico español, siendo claro ejemplo de ello el artículo 1.1 CE, con la propugnación de la libertad, la justicia, la igualdad y el pluralismo político como valores superiores del ordenamiento jurídico. Una previsión que, siguiendo a la principal doctrina, supone el compromiso del Estado con la defensa a ultranza, y en cualesquiera circunstancias, de unos valores superiores cuya «naturaleza supraconstitucional (...) les hace aparecer como los cimientos del edificio constitucional» ${ }^{25}$.

A mayor abundamiento, la Constitución española consagra unos principios generales del derecho —artículo $9.3-{ }^{26}$ que, informando todo el ordenamiento jurídico $^{27}$, funcionan a modo de concreción de los valores superiores del artículo 1.1 $\mathrm{CE}^{28}$. Pudiendo resumirse esos principios en los de seguridad jurídica y responsabilidad de los poderes públicos ${ }^{29}$, resulta lógico, como ya se ha apuntado, que el primero de ellos se vea afectado por la imposición de medidas de defensa no reguladas previamente por el ordenamiento. De ahí que, como ya decíamos al principio, el intento por normativizar al máximo las situaciones extraordinarias resulte la solución más adecuada, ello en contraposición con un derecho de necesidad que, superando a la opción regulatoria en agilidad y dinamismo, siempre podrá ser empleado como último recurso cuando la regulación positiva se antoje insuficiente ante la crisis surgida. Y respecto al principio de responsabilidad de los poderes públicos, requisito básico de todo Estado de derecho ${ }^{30}$, pervive para aquellas situaciones en las que la respuesta estatal ante el peligro se revele desproporcionada, lo cual nos lleva a hacer mención de otro criterio jurídico elemental a la hora de valorar la adecuación o no a derecho de las actuaciones estatales en respuesta a situaciones de emergencia constitucional: el principio de proporcionalidad.

Se trata, en efecto, de un criterio jurídico de obligado cumplimiento, tanto en relación con las situaciones de emergencia constitucional reglada —así se exige, por ejemplo, en el artículo 1.2 LOEAES_-, como con aquellas amenazas que escapan total o parcialmente a la regulación de emergencia previamente

24 Advirtiendo del uso indistinto que el Tribunal Constitucional hace de esos dos últimos términos, Torres del Moral, A., Principios de Derecho Constitucional Español. Tomo I, Madrid, Universidad Complutense de Madrid, 5. ${ }^{a}$ ed., 2004, pp. 58 a 60.

25 De Esteban, J., Derecho Constitucional. Tomo I, 2. ${ }^{\text {a }}$ ed., UCM, Madrid, 2001, p. 144, de ahí que el autor afirme el carácter intangible de los mismos. En la misma línea, LuCAS VERDú, P., «Artículo 1. ${ }^{\circ}$ : Estado social y democrático de derecho», en Alzaga Villaamil, Ó. (dir.), Comentarios a la Constitución Española de 1978, Edersa, Madrid, 1996, pp. 102 y 103.

26 Así denominados en virtud de STC 10/1989, de 24 de enero, FJ 3.

27 STC 4/1981, de 2 de febrero, FJ 1.

28 STC 27/1981, de 20 de julio, FJ 10.

29 Torres del Moral, A., Principios de Derecho Constitucional Español. Tomo I, op. cit., p. 60.

30 De Esteban, J., Derecho Constitucional. Tomo I, op. cit., p. 288. 
existente $^{31}$. Así, y de cara a impedir un ejercicio exorbitado del poder, el Tribunal Constitucional exige el respeto a un principio de proporcionalidad que, en palabras del máximo intérprete de la Constitución, exige la verificación de tres condiciones: «(i) adecuación de la medida al objetivo propuesto (juicio de idoneidad); (ii) necesidad de la medida para alcanzar su objetivo, sin que sea posible su logro a través de otra más moderada con igual eficacia (juicio de necesidad) y (iii) ponderación de la medida por derivarse de ella más beneficios o ventajas para el interés general que perjuicios sobre otros bienes o valores en conflicto (juicio de proporcionalidad en sentido estricto) ${ }^{32}$.

Ahora bien, el protagonismo que adquiere este principio a la hora de resolver sobre la pertinencia de las medidas de emergencia constitucional no debe llevarnos al error de fiar el diagnóstico final a la aplicación exclusiva de ese criterio de interpretación que, como el Tribunal Constitucional recuerda, debe ser tenido en cuenta en conexión con otros preceptos constitucionales ${ }^{33}$. Aunque hablaremos sobre ello más tarde ${ }^{34}$, un claro ejemplo es lo sucedido durante la pandemia por COVID-19, con la suspensión en materia de derechos fundamentales impuesta bajo un instituto, el estado de alarma, condicionado por ciertas reglas constitucionales básicas como son las previstas en los artículos 53.1 CE - respecto al contenido esencial en la ordinaria limitación de derechos fundamentales- y 55.1 $\mathrm{CE}$ - reserva de suspensión general de ciertos derechos fundamentales en favor de los estados de excepción y de sitio, exclusivamente-

\section{A nivel internacional}

Analizada la cuestión a nivel interno, procede ahora hacer un breve repaso de los parámetros que, a nivel internacional, guían la respuesta de los Estados frente a las situaciones de crisis. En este sentido, y refiriéndonos al ámbito del Consejo de Europa, el artículo 15 del Convenio Europeo de Derechos Humanos - CEDH, en adelante- es claro cuando, tras reconocer la posibilidad de los Estados de derogar temporalmente ciertas obligaciones en tiempos de guerra o de cualquier otro peligro público que ponga en peligro la vida de la Nación, establece ciertas líneas infranqueables.

31 De hecho, al principio de proporcionalidad recurrió el Tribunal Constitucional al resolver sobre la prohibición de una manifestación a celebrarse el 1 de mayo en Vigo, ello en el contexto de una pandemia «de dimensiones desconocidas hasta la fecha. Desconocidas y, desde luego, imprevisibles cuando el legislador articuló la declaración de los estados excepcionales en el año 1981»-ATC 40/2020, de 30 de abril, FJ 4 -

32 STC 64/2019, de 9 de mayo, FJ 5. En la misma línea, por ejemplo, las SSTC 66/1995, de 8 de mayo, FJ 5; 55/1996, de 28 de marzo, FFJJ 6, 7, 8 y 9; 207/1996, de 16 de diciembre, FJ 4 e); 37/1998, de 17 de febrero, FJ 8; y 39/2016, de 3 de marzo, FJ 5.

33 STC 215/2016, FJ 8.

34 Vid. apartado III.3. 
Desde un punto de vista material, se impone el respeto, tanto al principio de proporcionalidad en la medida implementada como a las restantes obligaciones dimanantes del derecho internacional — por ejemplo, la prohibición de «discriminación alguna fundada únicamente en motivos de raza, color, sexo, idioma, religión u origen social», establecida en el artículo 4 del Pacto Internacional de Derechos Civiles y Políticos de 1966 o PIDCP_— ${ }^{35}$. Y también se reconoce el carácter absoluto del derecho a la vida del artículo $2 \mathrm{CEDH}$ - excepción hecha de las muertes resultantes de actos lícitos de guerra-, y el de la prohibición de la tortura - artículo $3 \mathrm{CEDH}$ - y de la esclavitud —artículo $4 \mathrm{CEDH}$ - . Además, y desde un punto de vista formal, cada Alta Parte Contratante que haga uso de la cláusula derogatoria tendrá que informar el Secretario General del Consejo de Europa acerca de las medidas adoptadas, de los motivos que llevaron a su imposición, así como de la fecha en la que decaigan las mismas.

Confirmada, también a nivel internacional, la subsistencia del derecho incluso ante las situaciones de emergencia más extremas, no acaban ahí, sin embargo, las referencias jurídicas al respecto. Y, es que, si nos fijamos en los trabajos realizados por la Comisión de Venecia al respecto, comprobamos la existencia de importantes parámetros orientativos de la actuación de los Estados en situaciones de crisis. Unos criterios que, habiendo sido igualmente asumidos en el ámbito de la Unión Europea ${ }^{36}$, podrían sintetizarse de la siguiente forma ${ }^{37}$.

Empezando por el primero de ellos, consiste en el respeto a los principios de legalidad o de Estado de derecho, vinculados por definición al de seguridad jurídica. Ello se traduce, por ejemplo, en la conveniencia, no solo de que las normas propias de los estados de emergencia existan previamente a la declaración de los mismos, sino de que sean todo lo claras y detalladas que sea posible. Es preferible huir, por lo tanto, de los clausulados abiertos ${ }^{38}$, como igualmente explicitados han de estar los términos en los que, llegado el caso, el Parlamento puede delegar poderes extraordinarios en el Ejecutivo, según lo previsto en la normativa de emergencia ${ }^{39}$. Y eso que ya sabemos que, por grandes que sean los

35 En este sentido, por ejemplo, las SSTEDH de 10 de julio de 2001, Asunto Marshall c. Reino Unido; de 25 de mayo de 1993, Asunto Brannigan y McBride c. Reino Unido; o de 16 de septiembre de 2014, Asunto Hassan c. Reino Unido-.

36 Muestra de ello es, por ejemplo, la Resolución del Parlamento Europeo de 13 de noviembre de 2020, sobre el impacto de las medidas relacionadas con la COVID-19 en la democracia, el Estado de derecho y los derechos fundamentales (20020/2790-RSP-).

37 Seguimos, para ello, a Castellà Andreu, J. M., «La Comisión de Venecia y los estados de emergencia: la necesaria preservación del estado de derecho y la democracia constitucional durante la crisis de la COVID-19», en Biglino Campos, P. y Durán AlBa, F. (dirs.) Los Efectos Horizontales de la COVID sobre el sistema constitucional, Colección Obras Colectivas, FMGA, Zaragoza, 2021, pp. 12 y ss.

38 Caso del artículo 16 de la Constitución francesa, cuando alude a «las medidas exigidas por tales circunstancias».

39 CDL-AD(2020)018, Informe Provisional sobre las medidas adoptadas en los Estados miembros de la UE como resultado de la crisis del COVID-19 y su impacto en la democracia, el Estado de derecho y los derechos fundamentales, (Estrasburgo, 8-9 de octubre de 2020), párrafo 58. 
esfuerzos por regular la excepción, esta es imprevisible por naturaleza, lo cual lleva a que, en ocasiones, ciertas medidas no se encuentren previa y expresamente positivadas —el ejemplo más común y reciente lo constituye la pandemia por COVID-19-. Pero claro, ello no debe ser óbice para exigir que el salto al vacío de la desregulación se produzca a través del instrumento jurídico más ajustado - por su casuística, las medidas aplicables y sus correspondientes garantías- a la crisis sobrevenida.

Un segundo parámetro internacional de actuación lo encontramos en el principio de necesidad. Ello conlleva que, durante la situación de emergencia — declarada $0 \mathrm{no}^{40}$-, solo quepan las invasiones sobre derechos fundamentales y las alteraciones en la separación de poderes que resulten imprescindibles para ayudar a superar la situación extraordinaria. Y, por descontado, el objetivo de esas medidas debe ser exclusivamente el de la conjura del peligro en cuestión ${ }^{41}$. Nos encontramos ante un principio, el de necesidad, consolidado en el derecho internacional - también a nivel interno- y respecto de cuya observación el Tribunal Europeo de Derechos Humanos — en adelante, TEDH - concede a los Estados un gran margen de apreciación, que no discrecionalidad absoluta ${ }^{42}$.

Como tercer criterio aplicable nos encontramos con el principio de proporcionalidad stricto sensu, el cual exige que las modificaciones introducidas a raíz de la situación extraordinaria sean proporcionales, tanto en su alcance como en su extensión, a la naturaleza y gravedad de la amenaza surgida. En consecuencia, serán contrarias a derecho, por ejemplo, aquellas alteraciones en la distribución del poder que, aun pudiendo ser adecuadas o útiles de cara a solventar el peligro, supongan un cambio permanente o de larga duración en el modo en que se distribuye el ejercicio de los poderes del Estado ${ }^{43}$. De igual modo, e incidiendo nuevamente en el margen de apreciación de que disfrutan las autoridades estatales en este ámbito, el TEDH ha rechazado que la lucha contra el terrorismo justifique la adopción de cualesquiera medidas, lo cual le ha llevado, por ejemplo, a tachar de desproporcionadas, por discriminatorias, algunas de las decisiones impuestas por las autoridades del Reino Unido en materia de lucha antiterrorista ${ }^{44}$. Como sucede con el criterio de la necesidad, al que se encuentra estrechamente ligado, estamos ante un principio consolidado a nivel europeo y nacional.

40 Aunque como se señala en CDL-AD (2020) 018 (...), párrafo 29, es preferible que así sea.

41 CDL-AD(2020)018 (...), párrafo 23.

42 STEDH, de 18 de enero de 1978, Asunto Irlanda c. Reino Unido, párrafo 207. En ese mismo sentido, García Roca, J., «La muy discrecional doctrina del margen de apreciación nacional según el Tribunal Europeo de Derechos Humanos: soberanía e integración», Teoría y Realidad Constitucional, n. ${ }^{\circ}$ 20, 2007, p. 127.

43 CDL-PI(2020)003 (...), p. 5, en la que se explicita la conexión de la proporcionalidad con el principio de temporalidad. Por eso, inadecuada conforme a estos principios se antoja la prórroga del tercer estado de alarma decretado en España contra la COVID-19 — vid. párrafos finales del apartado III.3—.

44 STEDH, de 19 de febrero de 2009, Asunto A. y otros c. Reino Unido, Gran Sala, párrafo 190, en concreto, porque las restricciones impuestas «discriminaban injustificadamente entre los nacionales y los no nacionales». 
En adición a todo lo anterior, y de forma ya más resumida, un cuarto criterio de valoración es el que hace referencia al carácter expreso de la proclamación de las situaciones jurídicas de emergencia, debiéndose evitar los regímenes extraordinarios de facto. De hecho, y en la línea de lo ya apuntado antes, tanto el CEDH como el PIDCP condicionan la suspensión de las obligaciones contraídas por los Estados Partes a la notificación de tal circunstancia y la igual indicación de los motivos concretos de dicha medida ${ }^{45}$. Se trata esta de una formalidad que, si nos fijamos en lo sucedido durante la pandemia por COVID-19, apenas ha sido observada entre los Estados miembros del Consejo de Europa a la hora de imponer límites extraordinarios en materia de derechos fundamentales ${ }^{46}$.

A modo de quinto parámetro opera el principio de excepcionalidad, necesario por la dificultad, ya aludida, de predecir con total precisión una situación de emergencia concreta, lo cual convierte en inevitable la existencia de un cierto grado de vaguedad en la regulación previa de la misma. Ahora bien, con el fin de evitar interpretaciones interesadas, resulta aconsejable que los supuestos habilitantes de la aplicación de medidas excepcionales sean descritos de manera que su aplicación solo tenga lugar en caso de peligro real para la vida de la Nación ${ }^{47}$. Además, el principio de excepcionalidad lleva consigo aparejada la imposibilidad de proceder a la reforma de la Constitución en tanto no haya decaído la situación de crisis ${ }^{48}$.

En sexto lugar, la Comisión de Venecia incide en la necesidad de distinguir entre los distintos — en su caso — estados de emergencia previamente regulados, de modo que no toda amenaza sea tratada de la misma forma. El objetivo principal, evitar confusiones entre los diferentes regímenes de emergencia, circunstancia que podría ser aprovechada por la autoridad estatal competente para asumir cotas de poder aún mayores, prescindiendo de las necesarias garantías establecidas al efecto ${ }^{49}$.

En séptimo término, la situación de emergencia declarada ha de respetar el principio de temporalidad —estrechamente vinculado a los principios de necesidad y proporcionalidad ${ }^{50}$ — lo cual significa, por ejemplo, que toda alteración en la distribución de poderes ha de finalizar, como tarde, una vez haya concluida aquella. Ahora bien, ello no debería ser impedimento para que, una vez decaído el régimen

45 CDL-PI(2020)003 (...), p. 5.

46 En concreto, hasta el 30 de junio de 2021, solo diez Estados - Armenia, Estonia, Georgia, Letonia, Macedonia del Norte, Moldavia, Rumanía, San Marino y Serbia - habían cumplido con el requisito de la notificación previsto en el artículo 15.3 CEDH — https://www.coe.int/en/web/conventions/derogations-covid-19-. Sobre la cuestión, BonET PÉREZ, J., «El Estado de alarma en España y la cláusula derogatoria del Convenio Europeo para la Protección de los Derechos Humanos y Las Libertades Fundamentales», RDCE, n. ${ }^{\circ}$ 67, 2020, pp. 873-919.

47 CDL-AD(2016)006, Opinión sobre el Proyecto de Ley Constitucional sobre la «Protección de la Nación» de Francia, (Venecia, 11-12 de marzo de 2016), párrafo 28. En CDL-PI(2020)003, (...), p. 8.

48 CDL-AD(2017)005, Turquía - Dictamen sobre las enmiendas a la Constitución aprobadas por la Gran Asamblea Nacional el 21 de enero de 2017 y que se someterán a referéndum nacional el 16 de abril de 2017 (Venecia, 10 y 11 de marzo de 2017), párrafos 27 y ss. En CDL-PI(2020)003, (...), p. 27.

49 CDL-AD(2017)005 (...), párrafo 73. En CDL-PI(2020)003, (...), p. 8.

50 CDL-AD(2020)018 (...), párrafo 95. 
jurídico de emergencia, las circunstancias aún anormales puedan requerir la aplicación de normativa especial. Pero, de ser ese el caso, será obligatoria la igual aplicación de los principios de «controles y equilibrios» —o check and balances— entre poderes y de derechos adquiridos. Asimismo, las medidas de emergencia habrán de cesar en el momento en el que ya no sean necesarias ni proporcionales ${ }^{51}$.

Como octavo criterio aplicable a las situaciones de emergencia, la Comisión de Venecia se refiere al aseguramiento de un efectivo control parlamentario y jurisdiccional, tanto respecto de la declaración y posible prolongación del régimen de emergencia ${ }^{52}$, como de la activación y aplicación de los poderes de emergencia a él $\operatorname{asociados}^{53}$. En cuanto a la fiscalización parlamentaria, la realidad demuestra que puede tener lugar ex ante - por ejemplo, por la necesidad de autorización y/o prórroga del régimen jurídico extraordinario a activar- y ex post — sería el caso de la creación de una comisión de investigación una vez decaídas las medidas de emergencia- Y Y algo parecido sucede si hablamos de control jurisdiccional, pues hay casos en los que este es condición imprescindible para la imposición de medidas extraordinarias, quedando igualmente abierta la puerta a posteriores fiscalizaciones, ya sea a nivel interno - se prefiere el control jurisdiccional constitucional al ordinario- como en el ámbito internacional, Tribunal Europeo de Derechos Humanos, al frente. De igual modo, la Comisión de Venecia insiste en la necesidad de garantizar la independencia de los tribunales y el mantenimiento de su funcionamiento incluso en situaciones de emergencia, ello a excepción de los casos de absoluta necesidad o cuando ello sea materialmente imposible ${ }^{54}$.

A modo de noveno parámetro encontramos el de la predictibilidad de la normativa de emergencia, lo cual implica la conveniencia de su regulación constitucional para, en un momento posterior, ser detallada en una ley separada. Es preferible, además, que la norma de desarrollo revista naturaleza orgánica o constitucional y que haya sido previamente aprobada en el Parlamento, antelación igualmente exigible respecto de los decretos de emergencia y otras medidas de urgencia, siempre que ello sea posible $e^{55}$.

Por último, y a modo de décimo principio, la Comisión de Venecia cita el de la cooperación leal entre las instituciones estatales, cuestión esencial si lo que se desea es una gestión eficaz y coordinada de la crisis ${ }^{56}$. Esto se concreta, por ejemplo, en la necesidad de una actitud responsable por parte de las instituciones del Estado implicadas, ello a los efectos de lograr el mayor consenso político, tanto a los efectos de la activación de la normativa de emergencia, como de cara a su posterior control parlamentario. En este sentido, resulta aconsejable que Gobierno y

51 CDL-AD(2020)018 (...), párrafos 25 a 27.

52 De nuevo, el problema de la prórroga de seis meses decretada en España — vid. apartado III.3-.

53 CDL-PI(2020)005rev (...) párrafo 14.

54 CDL-PI(2020)005rev (...) párrafo 89.

55 CDL-PI(2020)005rev (...) párrafo 15.

56 CDL-PI(2020)005rev (...) párrafo 16. 
oposición aparquen todo interés partidista que obstaculice la adopción de las medidas requeridas para poner fin al problema surgido.

\section{A VUELTAS CON LA INSUFICIENCIA PREVISORA DEL ARTÍCULO 116 CE Y DE LA LOEAES ANTE CIERTAS CRISIS SOBREVENIDAS}

Demostrada la pervivencia de la juridicidad incluso ante las situaciones de emergencia más inverosímiles, es hora de comprobar la manera en la que el derecho constitucional de excepción se ha manifestado en España desde la entrada en vigor de la Constitución de 1978. Pues bien, si «el mayor peligro inherente a cualquier gobierno de crisis es que hombres egoístas puedan pervertirlo para sus fines ${ }^{57}$, el constituyente español consagró una serie de mecanismos de emergencia constitucional, precisamente para lograr un abordaje de las situaciones de crisis lo más eficaz y garantista posible.

Porque, si hay algo pacífico es que, ya desde su entrada en vigor, la Constitución de 1978 se ha enfrentado a situaciones de grave tensión para el sistema. De hecho, la lucha contra el terrorismo ha sido una constante hasta nuestros días. De igual modo, en 1981 hubo de conjurarse un golpe de Estado militar que amenazaba con devolvernos a tiempos dictatoriales. Como crucial fue también la respuesta estatal dispensada en 2017 frente al desafío secesionista catalán, sin olvidarnos del estado de alarma declarado siete años antes a raíz del colapso del tráfico aéreo. Y hoy, con una serie de estados de alarma decaídos recientemente, seguimos haciendo frente a una inédita crisis sanitaria cuyas profundísimas heridas se proyectan a nivel político, jurídico, social y económico.

Dicho todo lo cual, y advertida la amplitud del tema, aquí nos centraremos en la que probablemente sea la figura doctrinal por excelencia a la hora de hablar de situaciones de anormalidad constitucional en España. Nos referimos a la de los estados de emergencia del artículo $116 \mathrm{CE}$, precepto estrechamente conectado con el artículo 55.1 CE, en cuanto que reserva a los estados de excepción y de sitio la facultad en materia de suspensión de derechos fundamentales. El estado de alarma queda, por lo tanto, fuera de tal posibilidad, extremo que ha dado lugar a un vivo debate con motivo de algunas de las medidas impuestas en la lucha contra la COVID-19.

Antes de analizar esta y otras cuestiones relacionadas, realicemos una breve descripción de los institutos consagrados en el artículo 116 CE. Así, y a modo de aproximación genérica, nos encontramos ante tres mecanismos jurídicos contemplados para otros tantos supuestos de hecho igualmente diferentes ${ }^{58}$ y

57 Loewenstein, Teoría de la Constitución, op. cit. p. 286

58 Fernández Segado, F., «La Ley orgánica de los estados de alarma, excepción y sitio», RDP, n. ${ }^{\circ} 11,1981$, p. 95; o Torres del Moral, A., Principios de Derecho Constitucional Español. Tomo I, 5. edición, Universidad Complutense Madrid, 2004, pp. 576 y 577. Matiza lo anterior, refiriéndose al estado de sitio, 
que, a grandes rasgos, podrían resumirse en los siguientes: el estado de alarma —artículo 116.2 CE_, para calamidades naturales, sanitarias y tecnológicas de gran magnitud —artículo 4 LOEAES —; el estado de excepción —artículo 116.3 CE—, para graves alteraciones del orden público, tales como las relativas al libre ejercicio de los derechos fundamentales, el normal funcionamiento de las instituciones democráticas o el de los servicios públicos esenciales para la comunidad —artículo 13.1 LOEAES—; y el estado de sitio —artículo 116.4 $\mathrm{CE}$ - en relación con actos de insurrección o ataque contra la soberanía, independencia, integridad territorial o el orden constitucional de España —artículo 32 LOEAES-.

Sentado lo anterior, nada impide que un peligro no conjurado a tiempo pueda devenir en otro mayor, requiriendo el recurso a varios de los estados citados. Nos referimos, por ejemplo, a la posibilidad de que el estado de excepción pueda revelarse insuficiente para restaurar la normalidad constitucional, haciendo necesaria la posterior declaración del estado de sitio $^{59}$. O a que, al estado de alarma inicial provocado por la pandemia por COVID-19, le hubiera seguido la correspondiente activación del estado de excepción, ello desde el momento en el que, alterado gravemente el funcionamiento de los hospitales públicos, el Gobierno impuso medidas suspensivas en materia de derechos fundamentales ${ }^{60}$.

Por lo demás, la activación de esos institutos de emergencia procederá únicamente cuando circunstancias extraordinarias hicieran imposible el mantenimiento de la normalidad a través de los poderes ordinarios, siendo además imperativo, primero, que las medidas adoptadas se ciñan a las estrictamente imprescindibles para asegurar el retorno a la situación preexistente y, segundo, que se apliquen de manera proporcionada a las circunstancias — artículo 1 LOEAES—. Ello amén de otras garantías, todas ellas plenamente coherentes con lo visto en el apartado II, al defender la subsistencia del derecho incluso ante las emergencias constitucionales no regladas o insuficientemente regladas ${ }^{61}$.

Llegado ya el momento de analizar la vertiente empírica del artículo $116 \mathrm{CE}$, razones de espacio nos obligan a un esfuerzo de síntesis que, cuando menos, pretende

Cruz Villalón, P., «El nuevo derecho de excepción», REDC, vol. 1, n. ${ }^{\circ}$ 2, 1981, p. 102, al señalar que «la fórmula del artículo 32.1 LODES contiene un posible elemento de gradualidad al dejar constancia que debe tratarse de insurrecciones o actos de fuerza "que no pueda(n) resolverse por otros medios"...».

59 En este mismo sentido, Serrano Alberca, J. M., "Artículo 116», en Garrido Falla, F. (dir.) Comentarios a la Constitución, Civitas, Madrid, 1985, pp. 1775 y 1776; y GARRIDo LóPEz, C., «Sobre el estado de sitio, su régimen jurídico y el control jurisdiccional de su declaración», RDP, n. ${ }^{\circ}$ 68, 2007, pp. 110 y 111.

60 Vid. apartado III.3.

61 Nos referimos, por ejemplo, a la prohibición de disolución del Congreso en vigencia de los estados excepcionales y la no interrupción del funcionamiento de las Cámaras —artículo 116.5 CE—; la no modificación del principio de responsabilidad del Gobierno durante ese tiempo —artículo 116.6 CE—; el control parlamentario establecido frente a la concentración extraordinaria de poderes ejecutivos —artículos 116.2, 116.3 y 116.4 CE_- o la prohibición de iniciar una reforma constitucional en vigencia de alguno de los tres estados descritos — artículo 169 CE-. 
ilustrar en qué medida, ciertas crisis propias de dicho precepto ${ }^{62}$ acabaron derivando, por una razón u otra, en un desbordamiento - a veces conforme a derecho y, en otras ocasiones, injustificado_ del marco jurídico previsto para ellas. Veamos, a continuación, hasta qué punto es eso cierto.

\section{El golpe de Estado del 23-F y la imposibilidad práctica de declarar el estado de sitio}

Comenzamos estudiando muy brevemente la respuesta ofrecida por don Juan Carlos I tras el golpe de Estado perpetrado el 23 de febrero de 1981. Y, es que, no estando en el imaginario del poder constituyente español la posibilidad de que el Congreso de los Diputados y el Gobierno pudieran ser tomados como rehenes - lo cual hacía imposible la declaración del estado de sitio $^{63}$ — , la necesidad de preservación del orden constitucional acabó justificando la extralimitación constitucional protagonizada por el Jefe del Estado. Nos referimos a su actuación «ejercitando el poder, por sí mismo, del mando supremo de las fuerzas armadas, para salvar al Estado constitucional democrático» ${ }^{64}$.

Tratándose, en definitiva, de un supuesto de emergencia constitucional insuficientemente regulado, es en estos casos cuando, en la línea de lo ya apuntado en su momento, cabe hablar de la aplicación del verdadero derecho constitucional de excepción ante situaciones de necesidad o de fuerza mayor. Porque, en contra de lo señalado por una parte minoritaria de la doctrina, lo cierto es que, cuando el Jefe del Estado asumió el mando supremo de las Fuerzas Armadas de forma efectiva, no lo hizo a modo de confirmación de la existencia de una «suerte de reserva última de poder» en su favor ${ }^{65}$.

62 Dejamos pues fuera otras situaciones que, según la doctrina, bien podrían justificar o haber justificado la igual aplicación del artículo $116 \mathrm{CE}$. En este sentido, por ejemplo, la crisis provocada por el hundimiento del Prestige en el año 2002; CRUZ Villalón, P., «Veinticinco años de normalidad constitucional», RDP, n. ${ }^{\circ}$ 58-59, 2003-2004, p. 23-; o el estado de sitio para conjurar el desafío secesionista en Cataluña, si el recurso al artículo 155 CE resultara insuficiente, DE EsTEBAN, J., «Hacia la independencia catalana II», Fundación para la libertad, 29 de mayo de 2013, https://paralalibertad.org/hacia-la-independencia-catalana-ii/; o GómEz OrFANEL, G., «Las medidas y la aplicación del artículo 155 a Cataluña», REDC, n. ${ }^{\circ} 120,2020$, p. 352-.

63 Artículo 116.4 CE: «El estado de sitio será declarado por la mayoría absoluta del Congreso de los Diputados, a propuesta exclusiva del Gobierno. El Congreso determinará su ámbito territorial, duración y condiciones».

64 Aragón Reyes, M., «Veinticinco años de monarquía parlamentaria», REDC, n. ${ }^{\circ}$ 70, 2004, p. 23.

65 Como defiende García de Enterría, E., «Prólogo», La caracterización jurídica de las Fuerzas Armadas. Madrid. Centro de Estudios Constitucionales, 1987, pp. XXI a XXIV. De igual opinión, Herrero R. DE Miñón, M., «La Posición constitucional de la Corona», Estudios sobre la Constitución española. Homenaje al Prof. Eduardo GARCÍA DE ENTERRÍA, Tomo III, Civitas, Madrid, 1991, pp. 1936 a 1939. Por el contrario, sostienen el carácter simbólico del mando, ARAGón REYES, M., «Veinticinco años de monarquía parlamentaria», op. cit., p. 23; o Torres Del Moral, A., «Veinticinco años de Monarquía parlamentaria», RDP, n. ${ }^{\circ}$ 58-59, 2003-2004, p. 436. En una posición intermedia se sitúa DE OTTO, I., «El mando supremo de las Fuerzas Armadas», REDC, n. ${ }^{\circ} 23,1988$, pp. 14 y 40 y ss., para quien «es claudicación inadmisible del 
Lo que ocurrió es que, a la vista de la situación de necesidad surgida, hubo que decidir entre respetar la regulación positiva, con las evidentes consecuencias que ello habría tenido ante el golpe de Estado militar o, por el contrario, adoptar una actitud más expeditiva. La opción escogida fue la segunda y se hizo por medio de la figura del Rey don Juan Carlos I, que llevó a cabo una actuación plenamente respetuosa con las reglas, principios y valores esenciales del sistema democrático, tratando de «conservar el estado de cosas constitucional» ${ }^{66}$.

Sentada la adecuación a derecho de la actuación llevada a cabo, y partiendo del marco de nuestro sistema parlamentarista, a la vista está la dificultad de tratar de suplir la laguna jurídica a futuro, pues ello supondría tener que conferir poderes de emergencia a órganos ajenos al control de las Cortes Generales. Siendo, en ocasiones, más recomendable que la excepción continué siendo precisamente eso, el ejemplo nos sirve, además, para descartar que la concentración de poder en una situación de emergencia constitucional deba ser siempre protagonizada por el Ejecutivo ${ }^{67}$, aunque así es previsible que suceda en la inmensa mayoría de las situaciones.

\section{El estado de alarma ante el colapso del tráfico aéreo. Una emergencia constitucional... ¿insuficientemente reglada?}

Fijándonos ahora en lo sucedido con motivo de la primera activación del estado de alarma — año 2010 - desde la entrada en vigor de la Constitución española de 1978, partimos de la inadecuación de la respuesta gubernamental a lo previsto en la Constitución y en la LOEAES. Y lo hacemos en relación con una situación de crisis que, no está de más recordar, tuvo su origen en el enquistado conflicto laboral mantenido entre el colectivo de controladores aéreos y la Agencia Española de Navegación Aérea —AENA—, todo lo cual desembocó en el

constitucionalista limitarse a considerar las órdenes regias como anormalidad justificada por la anormalidad». Para el autor, la actuación regia queda avalada, desde un punto de vista del derecho constitucional positivo, por la facultad de «mando supremo de las fuerzas armadas» que le atribuye la Constitución, entendido en el sentido de facultad para impartir órdenes, aunque no en sentido político o militar, sí desde el punto de vista «de la conducción de una determinada unidad, de un elemento integrante de la organización militar». Más al respecto, en LAfuente BALle, J. M., «De cómo opera en la práctica el mando militar del Rey», RDP, n. ${ }^{\circ} 36$, 1992, pp. 321 y ss.

66 Belda Pérez-Pedrero, E., «23 de febrero de 1981: la reinterpretación de jurídica de un suceso propio de períodos de transición», $R E P,{ }^{\circ} .^{\circ} 155,2012$, p. 60, si bien matizando, frente a la doctrina del efectivo poder militar asumido por el Rey, que este «animó a los mandos a permanecer dentro del orden constitucional, ejercitando funciones y actos constitucionalmente admisibles, aunque formalmente se pudieran revestir de órdenes o comprenderse así desde la opinión pública o los mismos receptores».

67 Aunque, como señala Aragón Reyes, M., «Veinticinco años de monarquía parlamentaria», op. cit., p. 23, «fue la decisiva intervención del Monarca, defendiendo la Constitución, la que evitó que el golpe se consumara», Belda Pérez-Pedrero, E., «23 de febrero de 1981: la reinterpretación de jurídica de un suceso propio de períodos de transición», op. cit., p. 61, prefiere hablar de una crisis que «la vivió y afrontó todo el sistema. (...) Se trata de romper el esquema de pensamiento en el cual un golpe militar fue abortado por los mandos superiores y, en este caso, por su máximo Jefe formal». 
colapso del tráfico aéreo del país, al optar aquellos por el abandono masivo de sus puestos de trabajo.

La cuestión reside en determinar si la extralimitación jurídica se debió a la naturaleza no reglada o insuficientemente reglada del fenómeno y, por tanto, las medidas impuestas quedaban amparadas por el derecho de necesidad o, por el contrario, la normativa preexistente era suficiente para abordar la crisis sobrevenida.

Porque, de lo que no hay duda es del acierto práctico que, para la solución del problema, supuso la decisión gubernamental de conferir a todos los controladores al servicio de AENA la consideración de personal militar, ello mediante la aprobación del RD 1673/2010, de 4 de diciembre, de declaración del estado de alarma $^{68}$. La cuestión es que, como bien se nos apunta desde la doctrina, «de lo que se trata aquí es de valorar no la eficacia, sino la corrección jurídica de las medidas acordadas» ${ }^{69}$, y a ello dedicamos estas líneas. Pero antes de eso, simplemente añadir que, habiendo sido declarado por un período inicial de quince días, el estado de alarma fue objeto de una prórroga de otros treinta, ello en virtud del RD 1717/2010, de 17 de diciembre, previa autorización del Congreso de los Diputados dispensada en sesión de 16 de diciembre. En suma, el estado de alarma se mantuvo en vigor desde el 4 de diciembre hasta las veinticuatro horas del 15 de enero del año $2011^{70}$.

Realizado un somero resumen de los antecedentes de hecho es hora ya de exponer, aunque sea muy brevemente — porque al respecto hay ya mucho escrito ${ }^{71}$ las razones por las cuales entendemos que la respuesta estatal no fue conforme a derecho. No lo fue, básicamente, porque: 1) no concurrían los presupuestos habilitantes del artículo 4 LOEAES pues, en contra de lo argumentado por el Gobierno en el artículo 1 del RD 1673/2010, ni se produjo alguno de los desastres contemplados en el apartado a), ni existía una situación de desabastecimiento de productos de primera necesidad, como prevé el apartado d) ${ }^{72}$; 2) el artículo 117.5 CE reserva

68 Previamente, el Gobierno había dictado el RD 1611/2010, de 3 de diciembre, primero, confiriendo al Ministerio de Defensa la facultad temporal de control del tráfico aéreo; y segundo, encargando al Jefe de Estado Mayor del Ejército del Aire la activación de los recursos en materia de control del tráfico aéreo propios de dicho Ministerio, así como la impartición a los controladores aéreos de la orden de regresar a sus puestos de trabajo. El problema estribaba en la imposibilidad jurídica de someter a dicho colectivo, en cuanto que personal civil, al mando del Jefe de Estado Mayor del Ejército del Aire, lo que llevó al Gobierno a declarar el estado de alarma para atribuir a dichos trabajadores la condición de personal militar.

69 Requejo Rodríguez, P., «Teoría vs. práctica del estado de alarma en España», Constitución y democracia: ayer y hoy. Libro bomenaje a Antonio Torres del Moral, vol. II, Universitas, 2012, p. 1505.

70 Superada la situación de urgencia, el Gobierno devolvió a AENA las competencias de dirección del control de la circulación aérea general al Ministerio de Defensa - RD 28/2011, de 14 de enero, por el que se deroga el RD 1611/2010, de 3 de diciembre, por el que se encomienda transitoriamente al Ministerio de Defensa las facultades de control de tránsito aéreo atribuidos a la entidad pública empresarial AENA-.

71 Nosotros lo hicimos, citando a la principal doctrina, en La defensa de la Constitución. El derecho de emergencia constitucional y el artículo 55 CE, Thomson Reuters-Aranzadi, Navarra, 2020, pp. 148 y ss.

72 Esto es básico porque, cuando el artículo 4 c) LOEAES prevé la «paralización de servicios públicos esenciales para la comunidad» como causa justificante de la declaración del estado de alarma —el Ejecutivo la 
exclusivamente al estado de sitio la posibilidad de que el personal civil pueda ser sometido a la jurisdicción militar ${ }^{73} ; 3$ ) al margen de su excesiva duración ${ }^{74}$, la prórroga en sí fue contraria al artículo 1.2 LOEAES pues, en el propio preámbulo del RD 1717/2010, se aseguraba que el servicio de control del tráfico aéreo se prestaba ya «en condiciones de normalidad» ${ }^{75}$.

Sentada la incongruencia entre la actuación gubernamental y la regulación del estado de alarma, lo siguiente es determinar si ese exceso vino avalado por la existencia de una deficiencia regulatoria y el surgimiento de la consiguiente situación de necesidad. Una argumentación que, en ausencia de un pronunciamiento sobre el fondo por parte del Tribunal Constitucional ${ }^{76}$, nosotros rechazamos de plano. Y lo hacemos desde el momento en que la grave alteración en el normal funcionamiento del tráfico aéreo, en cuanto que servicio público esencial para la comunidad, sin ninguna circunstancia adicional, no es, como decíamos, presupuesto para la declaración del estado de alarma sino para el de excepción —artículo 13.1 LOEAES-.

Partiendo de esa consideración, carece de relevancia, sobre todo, la pregunta sobre la existencia o no de una situación de necesidad que hiciera imprescindible decretar la militarización de los controladores aéreos pese a ser una medida constitucionalmente reservada al estado de sitio. Y, es que, la improcedencia de esa

invocó en conexión con los apartados a) y d) mencionados-, lo hace bajo la condición de que «no se garantice lo dispuesto en los artículos veintiocho, dos, y treinta y siete, dos, de la Constitución, y concurra alguna de las demás circunstancia o situaciones contenidas en este artículo». En definitiva, el Gobierno procedió a una «interpretación más que forzada de los supuestos de hecho habilitantes», como bien se advierte en ÁLvarEZ Conde, E. y Tur Ausina, R., Derecho Constitucional, 8. ${ }^{a}$ edición, Tecnos, Madrid, 2018, p. 568.

73 En esa misma línea, Vera SANTOS, J.M., «Secesión y derecho de excepción. A vueltas con el estado de alarma en España», Consecuencias jurídicas de la secesión de entidades territoriales. Una visión para España, Thomson Reuters-Aranzadi, Navarra, 2020, pp. 456 y ss.; o Vidal Prado, C. y Delgado Ramos, D., "Algunas consideraciones sobre la declaración del estado de alarma y su prórroga», REDC, n. ${ }^{\circ}$ 92, 2011, p. 260. A favor, en cambio de la posibilidad de la militarización decretada, JimÉnEz Villarejo, J., «Militarización de los controladores», El País, 13 de diciembre de 2010, edición digital; PunsET, R., «El estado de alarma, cuestión de interpretaciones», La Nueva España, 9 de diciembre de 2010, edición digital; o GARRIDO López, C., «La naturaleza bifronte del estado de alarma y el dilema limitación-suspensión de derechos», TRC, n. ${ }^{\circ} 46,2020$, pp. 392 y 393.

74 Nos remitimos, en este punto, a la reflexión realizada al final del apartado III.3, a raíz de la prórroga de seis meses aprobada sobre el tercer y último estado de alarma decretado en la lucha contra la COVID-19.

75 Aunque es cierto que negando, a continuación, que el funcionamiento del sistema aeroportuario fuera «idéntico al de situaciones de normalidad anteriores». En cualquier caso, para mantener esas medidas excepcionales, el Gobierno debería haber sido más preciso al describir el estado de las cosas, no cabiendo las prórrogas ante «una situación de incertidumbre», palabras del por aquel entonces Ministro de la Presidencia, Señor Ramón Jáuregui-Europapress, 16 de diciembre de 2010. De la misma opinión, Pulido QueCEDo, M., «La prórroga del estado de alarma "por incertidumbre" ", Actualidad jurídica Aranzadi, n. ${ }^{\circ} 813,2011$, p. 17; o Álvarez Conde, E. y Tur Ausina, R., Derecho Constitucional, op. cit., p. 569.

76 Ello al inadmitir a trámite los recursos de amparo planteados por el colectivo de controladores aéreos, pues entendió que eran actos o decisiones con rango o valor de ley. Al menos, sirvió para determinar la naturaleza jurídica y el rango de las decisiones o actos parlamentarios adoptados en relación con los estados de alarma, excepción y sitio. Al respecto, GARrido López, C., Decisiones excepcionales y garantía jurisdiccional de la Constitución, Marcial Pons, Madrid, 2021, pp. 153 y ss. 
actuación deviene insalvable desde el momento en el que tuvo lugar través del estado de alarma, en lugar de hacerlo al abrigo de un estado de excepción - $-\mathrm{y}$, si la regulación actual no gusta, debe cambiarse_-, que, eso sí, habría exigido la urgente reunión del Congreso de los Diputados para que su autorización no se demorase en demasía —artículo $116.3 \mathrm{CE}^{77}$.

Y respecto a esto último, simplemente apuntar que, aferrarse a la validez del estado de alarma, esgrimiendo para ello su mayor agilidad frente al estado de excepción, encierra un peligro potencialmente mayor que el que habría supuesto prolongar la parálisis del espacio aéreo hasta el momento de la autorización parlamentaria. Lo que se logra con ese enfoque es la relativización del derecho de emergencia constitucional en nuestro país, problema de fácil reproducción a futuro. Porque, siendo las extraordinarias alteraciones del orden público situaciones que requieren, por definición, una rápida respuesta estatal, siempre cabría recurrir al argumento de la mayor agilidad para, con ello, prescindir del permiso parlamentario previo, como se ha llegado a hacer respecto de la cual por COVID19. A ella nos referimos a continuación.

\section{COVID-19 y estado de alarma: el recurso abusivo al argumento de la insuficiencia regulatoria}

Analizada la respuesta estatal dispensada frente al 23-F de 1981, primero, y con motivo de la crisis de los controladores aéreos surgida en el año 2010, después, es momento de referirse a la discusión doctrinal suscitada en España a raíz de la respuesta ofrecida por el Gobierno frente a las consecuencias derivadas de la crisis sanitaria generada por la COVID-19. Una amenaza que, como veremos, evidencia a la perfección la capacidad limitada que tiene el Estado a la hora de tratar de regular previamente situaciones de emergencia constitucional.

En este sentido, cabe recordar que, el 14 de marzo de 2020, y ante la rápida expansión del virus en España, el Gobierno decidía activar el estado de alarma vía RD 463/2020 ${ }^{78}$, en lo que fue el inicio de unas injerencias en materia de derechos fundamentales sin parangón en la Unión Europea, comenzando por el

77 Igualmente favorables a la declaración del estado de excepción, VERA SANTOS, J. M., «Secesión y derecho de excepción. A vueltas con el estado de alarma en España», op. cit., pp. 469 y ss.; ReQUejo RodRíGuez, P., «Teoría vs. Práctica del estado de alarma en España», op. cit., p. 1503; o AвA CAToira, A., «El concepto jurisprudencial de límite de los derechos fundamentales», Anuario da Facultade de Dereito, n. ${ }^{\circ}$ 2, 1998 , pp. 335 y ss. En cambio, para Vidal Prado, C., y Delgado Ramos, D., «Algunas consideraciones sobre la declaración del estado de alarma y su prórroga», op. cit., p. 253, esa alternativa «habría abierto todavía más incertidumbres, y hubiera sido muy complicada de tomar de modo urgente». Por su parte, De Carreras, F., «Un claro supuesto de estado de alarma», La Vanguardia, 5 de diciembre de 2010, se muestra plenamente conforme con el estado de alarma declarado.

78 RD 463/2020, de 14 de marzo, por el que se declara el estado de alarma para la gestión de la situación de crisis ocasionada por el COVID-19. 
establecimiento de un confinamiento general casi total de la población durante las primeras semanas. Ese primer estado de alarma, con medidas que fueron suavizándose muy poco a poco, se prolongó hasta las 00:00 horas del 21 de junio $^{79}$, momento a partir del cual el Gobierno central dejaba en manos de las autonomías la responsabilidad principal en la lucha contra la pandemia ${ }^{80}$. Ya iniciado el otoño, el Ejecutivo decidía recurrir nuevamente al estado de alarma, si bien solo respecto de la Comunidad Autónoma de Madrid — RD 900/2020, de 9 de octubre- para, casi dos semanas después, proceder a una nueva declaración de alarma — RD 926/2020, de 25 de octubre - que, proyectada sobre todo el territorio nacional ${ }^{81}$, acabaría prorrogándose por un período único de seis meses - RD 956/2020, de 3 de noviembre-, previo permiso del Congreso de los Diputados. Finalizado ese último estado de alarma en la media noche del 8 al 9 de mayo de 2021, medidas como los toques de queda o los cierres perimetrales pasaban a depender de los gobiernos autonómicos y del visto bueno de los tribunales ${ }^{82}$.

Tras un breve relato de los hechos sucedidos, es hora de comprobar hasta qué punto, la insuficiencia regulatoria existente en determinados aspectos de la crisis sanitaria dio paso a la imposición de ciertas medidas que, afectando, como se ha visto, a los derechos fundamentales, tienen un encaje constitucional ciertamente controvertido. En este sentido, razones de espacio nos obligan a centrar la atención en lo sucedido con la libre circulación y elección de residencia de las personas —artículo 19 CE—, especialmente a raíz de la medida más invasiva de todas: los confinamientos generales casi totales de la población impuestos durante los inicios de la pandemia. Dedicando igualmente un breve espacio a la prórroga de seis meses aprobada sobre el tercer estado de alarma, nos remitimos a lo escrito en otro sitio a la hora de valorar otras medidas no regladas como fueron, sobre todo,

79 Al RD 463/2020, de 14 de marzo, por el que se declara el estado de alarma para la gestión de la situación de crisis ocasionada por el COVID-19, le siguieron los RRDD 465/2020, de 17 de marzo; 476/2020, de 27 de marzo; 487/2020, de 10 de abril; 492/2020, de 24 de abril, 514/2020, de 8 de mayo; 537/2020, de 22 de mayo; y 555/2020, de 5 de junio, ello sin perjuicio de que en algunas Comunidades Autónomas las medidas a él asociadas decayeran unos días antes.

80 Lo hizo vía Real Decreto-ley 21/2020, de 9 de junio, de medidas urgentes de prevención, contención y coordinación para hacer frente a la crisis sanitaria ocasionada por el COVID-19-. Especialmente crítico con esa decisión se muestra Aragón Reyes, M., «Epílogo», en Biglino Campos, P. y Durán Alba, F. (dirs.), Los Efectos Horizontales de la COVID sobre el sistema constitucional, Colección Obras Colectivas, Fundación Manuel Giménez Abad, Zaragoza, 2021, p. 10, al hablar de una «abstención del Estado en el cumplimiento diligente de sus competencias frente a la nueva ola de la pandemia, endosándoselas a las comunidades autónomas».

81 Pese a ese alcance global de la declaración, el Gobierno decidió que la autoridad competente fuera el presidente de cada comunidad autónoma, lo cual es contrario al artículo 7.1 LOEAES, que solo permite esa delegación «cuando la declaración afecte exclusivamente a todo o parte del territorio» de aquella, ARAGÓN Reyes, M., «COVID-19 y Estado autonómico», en Tudela ArANDA, J. (coord..), Estado autonómico y COVID19: un ensayo de valoración general, Fundación Manuel Giménez Abad, Zaragoza, 2021, p. 85-.

82 Dando lugar a una importante situación de inseguridad jurídica, como bien explica Tajadura TejadA, J., «Tribunales y COVID», El Correo, 12 de mayo de 2021. 
las afectaciones al derecho de sufragio en las elecciones gallegas y vascas, o la suspensión general de la libertad de empresa una vez había finalizado ya el confinamiento general ${ }^{83}$.

Acotado el objeto de la discusión, quisiéramos dejar sentada ya nuestra discrepancia frente a la mayoría de la doctrina que, desde el comienzo de la crisis, se ha valido de la deficiencia previsora de nuestro derecho de emergencia constitucional para, bajo el exclusivo prisma del derecho de necesidad y la aplicación del principio de proporcionalidad, bendecir un estado de alarma que, como ya se ha dicho, carece de la potestad para suspender derechos fundamentales —artículo 55.1 contrario sensu- ${ }^{84}$.

Porque ya hemos hablado de lo quimérico de lograr regular todas y cada una de las potenciales amenazas al orden constitucional que pueden manifestarse a lo largo del tiempo. Y también de la lógica de permitir la convivencia fáctica entre el recurso a los estados excepcionales y la apreciación del derecho de necesidad. El caso es que ello ha servido de excusa para utilizar los elementos de una u otra disciplina - estados de emergencia y derecho de necesidad- según mejor convenga. $Y$, es que, para actuar de forma adecuada frente a la anormalidad constitucional, resulta imprescindible que el salto que se produce desde la normatividad al vacío de la no regulación específica — ya sea total o parcial — tenga lugar de la manera más controlada posible. Esto es, valiéndose todo lo posible de aquellos instrumentos que, estando expresamente anticipados en la norma, favorezcan un tránsito por el derecho de emergencia constitucional y un posterior regreso a la normalidad lo más ordenado y garantista posible para el orden jurídico que se pretende proteger.

En este caso, la solución adecuada habría pasado por declarar el estado de excepción desde el mismo instante en que las ordinarias limitaciones de derechos fundamentales se revelaron insuficientes para superar la crisis sanitaria surgida. Porque, como ha reconocido el Tribunal Constitucional en una decisión sobre

83 Fernández de Casadevante Mayordomo, P., en Garrido López, C. (coord.), «La crisis de los controladores aéreos y la COVID-19 como emergencias constitucionales insuficientemente regladas. Propuestas de "lege ferenda" para el estado de alarma», Excepcionalidad y derecho: el estado de alarma en España, Fundación Manuel Giménez Abad, Zaragoza, 2021, pp. 377 y ss. Por otra parte, y respecto a las vulneraciones del principio de reserva de ley y la consiguiente lesión del principio de seguridad jurídica a lo largo de la pandemia, Tajadura Tejada, J., «El Estado de Derecho frente al COVID: reserva de ley y derechos fundamentales», Revista Vasca de Administración Pública, n. ${ }^{\circ}$ 120, 2021, pp. 137-175.

84 A pesar de que no es el formato científico ordinario, demostrar ese estado de opinión existente desde los inicios de la pandemia pasa por referenciar material publicado en medios de comunicación durante ese tiempo - un tanto de lo mismo cabe apuntar en relación con otras cuestiones relacionadas y que, por su trascendencia social, fueron objeto de igual debate doctrinal en los medios- Así, desde el principio, Cruz Villalón, P., «La Constitución bajo el estado de alarma», El País, 17 de abril de 2020; De La Quadra-Salcedo, T., «Límite y restricción, no suspensión», El País, 8 de abril de 2020; LópeZ GARrido, D., «Un estado de excepción sería inconstitucional», Eldiario.es, 11 de abril de 2020, https:// www.eldiario.es/tribunaabierta/excepcion-inconstitucional_6_1015658433.html; y PÉrEZ ROYO, J., «Estado de excepción material», Eldiario.es, 12 de marzo de 2020, https://www.eldiario.es/contracorriente/ excepcion-material_132_1001921.html. 
cuyos pormenores solo podemos hablar brevemente, el confinamiento general casi total de la población —artículo 7 del RD 463/2020 — supuso una auténtica suspensión de derechos fundamentales, debiéndose haber optado por el estado de excepción, en cuanto que instrumento más garantista ${ }^{85}$.

Con ello se despejan los temores expresados en otro trabajo previo, cuando hablábamos del exclusivo protagonismo que el Alto Tribunal -Auto 40/2020, de 30 de abril - había concedido al principio de proporcionalidad para resolver sobre las suspensiones de derechos fundamentales en los inicios de la pandemia —en ese caso, el derecho de reunión y manifestación del artículo 21 CE_— ${ }^{86}$. Por fortuna para el devenir de las garantías aplicables en vigencia del derecho de emergencia constitucional en España, la mayoría del Tribunal Constitucional — seis magistrados frente a cinco, que formulan otros tantos votos particulares - ha sido consciente de que, a la hora de estudiar la constitucionalidad o no de las invasiones decretadas sobre los derechos fundamentales en situaciones de anormalidad constitucional, la proporcionalidad no lo es todo. De hecho, su sola aplicación a la hora de decidir sobre la pertinencia del estado de alarma o de excepción en el caso que nos ocupa, no aclara nada ${ }^{87}$. Porque la Constitución reconoce, dentro de las medidas proporcionadas, tanto la posibilidad de las ordinarias limitaciones en materia de derechos fundamentales —artículo 53.1 CE_- como de las suspensiones — artículo $55 \mathrm{CE}$ — , dotadas estas últimas de unas garantías reforzadas.

Con lo que no estamos de acuerdo, en cambio, es con la fórmula empleada por el Alto Tribunal a la hora de identificar la existencia de ese segundo tipo de injerencias durante lo que duró el confinamiento. En concreto, porque descarta aplicar la técnica del deber de respeto absoluto al «contenido esencial» del derecho - artículo 53.1 CE—, cuando resulta que es la fórmula que sirve para delimitar la frontera entre las simples limitaciones o restricciones de derechos fundamentales, de un lado, y las suspensiones, de otro ${ }^{88}$. En su lugar, el máximo intérprete de la Constitución recurre al criterio de «la suspensión de la vigencia de un concreto derecho fundamental», entendido como «cesación» o situación en la que la facultad de ejercitar el derecho «deja pues de existir». Y lo hace para acabar afirmando que las restricciones impuestas vía artículo 7 RD 463/2020 sobre la libre circulación y elección de la propia residencia del artículo 19.1 CE

85 STC 148/2021, de 14 de julio, FFJJ 5 y 11.

86 Fernández de Casadevante Mayordomo, P., «Los derechos fundamentales en estado de alarma: una suspensión inconstitucional», Revista Vasca de Administración Pública, n. ${ }^{\circ} 119,2021$, pp. 79 y ss.

87 STC 148/2021, de 14 de julio, FJ 5, al señalar que «solo en el caso de que el derecho no haya quedado suspendido cabrá analizar si la limitación respeta las exigencias de la proporcionalidad». En contra, los votos particulares de los magistrados don Juan José González Rivas (puntos 4 y 5), don Andrés Ollero Tassara (puntos 2 y ss.), don Juan Antonio Xiol Ríos (puntos 17 y ss.), don Cándido Conde-Pumpido Tourón (punto 3), y doña María Luisa Balaguer Callejón (punto 3).

88 Cruz Villalón, P., Estados excepcionales y suspensión de garantías, op. cit.; p. 76; o ReQuejo RodríGuez, P., «Artículo 55», en Casas BaAmonde, M. E. y Rodríguez-Piñero y Bravo Ferrer, M. (dirs.), Comentarios a la Constitución Española, Boletín Oficial del Estado, Madrid, 2018, p. 1523. 
- y de soslayo, el derecho de mantener reuniones privadas de los artículos 18 y 21.1 CE - , fueron de naturaleza suspensiva, por convertir aquellas en irreconocibles, por suponer un «vaciamiento de hecho o, si se quiere, una suspensión del derecho» ${ }^{89}$

En realidad, se trata de un criterio ${ }^{90}$ hasta cierto punto compatible con la conceptualización que la jurisprudencia constitucional lleva a cabo respecto de lo que debe entenderse por contenido esencial, el cual se verá afectado si: 1) la norma encargada de regular el derecho invadido lo convierte en irreconocible o lo desnaturaliza; 2) ese derecho es sometido a semejantes restricciones que su ejercicio deviene imposible o más difícil de lo razonable, o se le protege de manera insuficiente ${ }^{91}$.

Ahora bien, dos son los principales problemas que, a nuestro modo de ver, se derivan de la técnica empleada por el máximo intérprete de la Constitución en esta ocasión. Respecto al primero, que la simple asociación entre suspensión y desaparición temporal del derecho implicaría dejar fuera del ámbito suspensivo medidas con base en el propio artículo $55 \mathrm{CE}$ que, suponiendo la pervivencia de una parte importante del derecho afectado, han sido reconocidas por el propio Tribunal como igualmente suspensivas ${ }^{92}$. Porque, para hablar de suspensión, no es necesario que el derecho deje de existir, cosa que, por cierto, tampoco sucede con la aplicación del artículo 7 RD 463/2020, en la medida en que establece algunas excepciones a esa prohibición general de circular. Y en cuanto al segundo inconveniente, resulta que, al evitar definir qué debe entenderse por núcleo y médula del derecho a la libertad de circulación y de elección de residencia, se facilita la labor de enjuiciamiento en el caso del artículo 7 RD 463/2020, sí, pero, al mismo tiempo, se pierde la oportunidad para aclarar, de cara al futuro, qué aspectos de ese derecho resultan indisponibles para las autoridades públicas si de

89 STC 148/2021, de 14 de julio, FJ 5 . Es básicamente por eso que acaba declarando inconstitucionales y nulos los apartados 1, 3 y 5 del artículo 7 -también los términos «modificar, ampliar o» del artículo 10.6, en la redacción dada por el artículo único, 2, del RD 465/2020, pero por otros motivos que se explican en el Fundamento Jurídico 9 de la propia Sentencia-.

90 En contra de atribuir un valor sustantivo al concepto suspensión de los derechos fundamentales, por entender que esta solo se produce si así se establece formalmente por las autoridades competentes, los votos particulares de los magistrados don Juan José González Rivas (puntos 2 y 3), don Juan Antonio Xiol Ríos (puntos 14 y ss.), y don Cándido Conde-Pumpido Tourón (punto 2). Como bien apunta la mayoría en la STC 148/2021, de 14 de julio, FJ 11, aceptar esa premisa violentaría la distinción constitucional entre limitación y suspensión, «convirtiendo la alarma en un sucedáneo de la excepción, pero no sometida a la «previa autorización» parlamentaria». Ello llevaría al absurdo de permitir al Gobierno suspender derechos sin decirlo, escapando a la previa discusión y autorización y con menos limitaciones en cuanto a la duración.

91 STC 11/1981, de 8 de abril, FJ 8.

92 Claro ejemplo de ello es la STC 199/1987, de 16 de diciembre, FJ 8, cuando establece límites muy específicos a la facultad del legislador a la hora de regular la suspensión en relación con el plazo máximo de duración de la detención preventiva — artículo 17.2 CE—, la inviolabilidad del domicilio —artículo 18.2 CE- y el secreto de las comunicaciones —artículo 18.3 CE—. Más en Fernández de Casadevante Mayordomo, P., «Los derechos fundamentales en estado de alarma: una suspensión inconstitucional», op. cit., pp. 71 a 74. 
limitaciones ordinarias hablamos — por ejemplo, en relación con los toques de queda o los cierres perimetrales-.

Mención aparte merece, de igual modo, el cambio de criterio adoptado por el Tribunal Constitucional en la misma sentencia cuando, al analizar otras injerencias sobre los derechos fundamentales producidas vía RD 463/2020, se limita a redirigir esas actuaciones a lo previsto en la LOEAES para el estado de alarma — también alude a legislación en materia de protección civil—y a aplicar, a continuación, el principio de proporcionalidad ${ }^{93}$. Así, y a pesar de que, por ejemplo, reconoce la existencia de reglas que «constriñen intensísimamente, con carácter temporal», el libre ejercicio de la actividad empresarial, acaba avalándolas, lo cual resulta incoherente con la argumentación mantenida por el Tribunal al hablar de la libertad de circulación ${ }^{94}$.

Sentado todo lo anterior, y no habiéndose cuestionado la proporcionalidad de las medidas suspensivas impuestas en la lucha contra la pandemia ${ }^{95}$, corresponde ahora hacer referencia a la argumentación esgrimida por el Tribunal Constitucional de cara a defender el estado de excepción como la opción jurídica adecuada en relación con las injerencias sobre la libre circulación ${ }^{96}$. Pues bien, es de aplaudir el hecho de que, frente a la corriente doctrinal mayoritaria, favorable a circunscribir el estado de excepción a las amenazas de naturaleza política ${ }^{97}$, el Tribunal Constitucional haya optado por una interpretación más amplia del concepto de orden público del artículo 13.1 LOEAES $^{98}$. De lo contrario, se estaría aceptando «el fracaso del Estado de derecho, maniatado e incapaz de encontrar una respuesta ante situaciones de tal gravedad $»^{99}$, habida cuenta de que el estado

93 STC 148/2021, de 14 de julio, FFJJ, 8, 9 y 10.

94 STC 148/2021, de 14 de julio, FJ 9.

95 En la STC 148/2021, de 14 de julio, FJ 11, se recuerda que las constricciones extraordinarias de la libertad de circulación por el territorio nacional impuestas por el artículo 7 —apartados 1, 3 y 5- del RD 463/2020 se orientaron a «la protección de valores e intereses constitucionalmente relevantes» y se ajustaron «a las medidas recomendadas por la Organización Mundial de la Salud en su documento "Actualización de la estrategia frente a la COVID-19” — 14 de abril de 2020—».

96 Igualmente favorables a la declaración del estado de excepción, por ejemplo, Aragón ReYes, M., «Hay que tomarse la Constitución en serio», El País, 13 de abril de 2020; Vera Santos, J. M., «Secesión y derecho de excepción. A vueltas con el estado de alarma en España», op. cit., pp. 469 y ss.; DíAz Revorio, F. J., «Desactivando conceptos constitucionales: la suspensión de derechos y los estados excepcionales», op. cit. p. 134; y Cuenca Miranda, A., "Alarma “excepcional”", Papeles FAES, n. ${ }^{\circ} 236,2020$, p. 5.

97 Entre otros, Cruz Villalón, «La Constitución bajo el estado de alarma», op. cit., De la QuADRA-SAlCEdo, T., «La aversión europea al estado de excepción», El País, 28 de abril de 2020; López Garrido, C., «Un estado de excepción sería inconstitucional», op. cit., y Presno Linera, M. A., «¿Por qué se decreta un estado de alarma y no de excepción por el coronavirus?», El Diario Montañés, 27 de marzo de 2020, https://www.eldiariomontanes.es/nacional/decreta-estado-alarma-20200327093825-ntrc.html? ref $=\mathrm{h}-$ ttps:\%2F\%2Fwww.google.es\%2F.

98 Expresamente en contra, los votos particulares emitidos por los magistrados don Juan Antonio Xiol Ríos (puntos 6 y ss.), don Cándido Conde-Pumpido Tourón (punto 4) y doña María Luisa Balaguer Callejón (punto 2). E igualmente partidarios de aplicar el estado de alarma en atención al presupuesto de hecho, los magistrados don Juan José González Rivas (punto 4) y don Andrés Ollero Tassara (puntos 3 y 5 ).

99 STC 148/2021, de 14 de julio, FJ 11. 
de alarma, previsto, como sabemos, para crisis sanitarias como la vivida - artículo 4 LOEAES — , no permite la suspensión de derechos fundamentales.

Se trata de una conclusión, la alcanzada por el Tribunal Constitucional, contraria, como decíamos, a la opinión doctrinal de quienes, escudados en la especial intensidad de la pandemia, han rechazado desde el principio el análisis jurídico desde la dicotomía ordinaria limitación-suspensión, centrando para ello su atención en las fronteras naturales del derecho ${ }^{100}$. Desde esa perspectiva doctrinal, la COVID-19 habría provocado una «afectación drástica del principio general de libertad» ${ }^{101}$ consagrado en el artículo 1.1 CE. Desbordado el marco constitucional $^{102}$, el estado de necesidad se abriría paso ${ }^{103}$, no estando la respuesta estatal sujeta a más parámetros constitucionales que el respeto al principio de proporcionalidad $^{104}$ y a los principios generales del derecho ${ }^{105}$.

El problema es que se trata de una aproximación demasiado simplista y peligrosa, ello por dos razones básicas. La primera, porque atribuir al coronavirus la responsabilidad exclusiva de las más graves afectaciones sobre los derechos fundamentales de nuestra historia moderna esconde una trampa: supone hacer automáticamente tabla rasa de los posibles errores cometidos a la hora de enfrentar la pandemia, ocultando que la mayoría de países de nuestro entorno lidiaron con la expansión del virus — con sus lógicos problemas y posteriores repuntes, sí — sin necesidad de recurrir, sobre todo, al confinamiento domiciliario casi total de la población ${ }^{106}$. Como si, por ejemplo, el tiempo de respuesta inicial ante la pandemia ${ }^{107}$, la estrategia adoptada ante la misma, la mejor o peor coordinación entre las distintas administraciones públicas, el previo estado del sistema sanitario, o el comportamiento más o menos responsable de la población a la hora de respetar las medidas, no fueran aspectos a valorar en un contexto de pandemia, pasada, presente o futura.

100 Por ejemplo, Cruz Villalón, P., «La Constitución bajo el estado de alarma», op. cit.; De LA QUADRA-SALCEDO, T., «Límite y restricción, no suspensión», op. cit.; y más recientemente, «La terrible confusión entre limitar y suspender derechos», Agenda Pública, 5 de julio de 2021, edición digital, https://agendapublica.es/la-terrible-confusion-entre-limitar-y-suspender-derechos/.

101 Cruz Villalón, P., «La Constitución bajo el estado de alarma», op. cit.

102 Pérez Royo, J., «Estado de excepción material», Eldiario.es, 12 de marzo de 2020; o López BASAguren, A., «¿Octavio y Catón en el Constitucional?», El País, 29 de junio de 2021, entre otros.

103 Cruz Villalón, P., «La Constitución bajo el estado de alarma», op. cit.

104 Como ya se ha indicado antes, los cinco votos particulares aluden igualmente al principio de proporcionalidad como parámetro de constitucionalidad aplicable al caso concreto.

105 Desde el principio, De la Quadra-Salcedo, T., «Límite y restricción, no suspensión», op. cit.; López Garrido, C., «Un estado de excepción sería inconstitucional», op. cit.; o Cruz Villalón, P., «La Constitución bajo el estado de alarma», op. cit. Por su parte, el ATC 40/2020, de 30 de abril, FJ 4, habla de una situación de «incertidumbre (...) acentuada y difícil de calibrar desde parámetros jurídicos», lo que hace pensar en un posicionamiento similar a los que acabamos de describir.

106 De hecho, fue el propio Gobierno el que, a través de su Ministro de Sanidad, reconoció — en comparecencia de 2 de junio de 2020_, que «España ha tenido el confinamiento más duro de los países de la Unión Europea», https://www.mscbs.gob.es/profesionales/saludPublica/ccayes/alertasActual/nCov-China/videosPrensa.htm.

107 Excesivo, por ejemplo, para De EstebAn, J., «El estado de alarma y el coronavirus», El Mundo, 18 de marzo de 2020; o Vírgala Foruria, E., El Independiente, 14 de marzo de 2020. 
Y respecto a la segunda razón de nuestra discrepancia, parte de algo que ya se ha apuntado con anterioridad y es que la LOEAES prevé, tanto el supuesto de calamidad inicial provocado por el coronavirus — estado de alarma-, como el que se produjo después como consecuencia del peligro de colapso de los hospitales públicos —estado de excepción-. Dicho de otro modo, es el propio ordenamiento jurídico el que, hace ahora cuarenta años, decidió anticiparse a los hechos, previendo la posibilidad de que una pandemia y sus efectos derivados afectasen al normal disfrute de los derechos fundamentales consagrados en la Constitución. Por lo tanto, «ni las apelaciones a la necesidad pueden hacerse valer por encima de la legalidad, ni los intereses generales pueden prevalecer sobre los derechos fundamentales al margen de la ley» ${ }^{108}$.

¿Que la LOEAES podía ser más precisa? Es obvio que sí — por eso convendría su reforma-, pues incluso las medidas contempladas para el estado de excepción se quedaron cortas. De hecho, el artículo 20.1 LOEAES habla únicamente de la posibilidad de «probibir la circulación de personas y vehículos en las horas y lugares que se determine», no de un encierro domiciliario casi total de la población. Ahora bien, el precepto se ajusta mucho mejor que el estado de alarma, al que solo le cabe la posibilidad de «limitar la circulación o permanencia de personas o vehículos en horas y lugares determinados, o condicionarlas al cumplimiento de ciertos requisitos» - artículo 11 a) LOEAES—. Y la cuestión es que, determinada la necesidad de confinar a la población en sus domicilios para frenar los contagios - nosotros no entramos en esa discusión-, habría resultado absurdo negar la imposición de tal medida por no encontrarse previamente regulada en el ordenamiento jurídico.

Estamos, por tanto, ante una medida - la del confinamiento general casi total - no reglada o insuficientemente reglada que, si se llega a adoptar con respeto a las reglas constitucionales establecidas en los artículos 55.1 y 116.3 CE - esto es, declarando el estado de excepción dada la existencia de suspensiones de derechos fundamentales-, habría sido salvada por el Tribunal Constitucional. Y habría representado además un perfecto ejemplo de lo que al principio de este estudio defendíamos que es para nosotros el auténtico derecho constitucional de excepción ${ }^{109}$. Porque, ante la emergencia constitucional no reglada en su totalidad, y partiendo siempre de las reglas básicas positivadas, es lógico que quepa la igual apreciación de ciertas situaciones de necesidad. Pero, en el presente caso, ese salto debería haberse llevado a cabo desde la figura del estado de excepción, lo cual habría implicado la necesidad de previa autorización del Congreso de los Diputados, con lo que todo ello significa a nivel de garantías ${ }^{110}$. Porque, si de res-

108 STC 148/2021, de 14 de julio, FJ 11.

109 Vid. apartado II.

110 En la importancia de la autorización parlamentaria previa a las suspensiones incide la STC 148/2021, de 14 de julio, FJ 11. De ahí nuestra sorpresa cuando De LA QuAdRA-SALCEDO, T., «La aversión europea al estado de excepción», op. cit., señala que «aplicar el estado de excepción en supuestos de la alarma 
peto al espíritu de la Constitución y de las leyes hablamos, lo relevante aquí, por encima de cualquier otra consideración, es la voluntad última del propio constituyente de reforzar el control parlamentario previo a la imposición de suspensiones en materia de derechos fundamentales. Esas son las reglas en tanto no se reforme nuestra Carta Magna.

Por cierto, nada ocurre porque el artículo 116.3 CE prevea una vigencia máxima de sesenta días — prórroga incluida - para el estado de excepción, pues siempre cabría proceder a una nueva declaración pasado ese tiempo. Lo contrario supondría, de nuevo, aceptar la incapacidad del Estado para defenderse antes las amenazas más insospechadas.

Por lo demás, y respecto a las restricciones a la libre circulación en horario nocturno — los denominados «toques de queda» - impuestas en aplicación del RD 926/2020, habrá que esperar a lo que el Tribunal Constitucional pueda decir en relación con el recurso de inconstitucionalidad interpuesto contra dicha norma ${ }^{111}$. Pareciendo descartar la doctrina general, en cualquier caso, el carácter suspensivo de la medida decretada ${ }^{112}$, lo cierto es que, incluso así — no todas las injerencias previstas en la LOEAES para los estados de excepción y sitio tienen carácter suspensivo- - y a la vista de las condiciones en que se estableció, se trata de una restricción con mejor encaje en el artículo 20.1 LOEAES, para el estado de excepción, que en el artículo 11 a) LOEAES, propio del estado de alarma ${ }^{113}$. Otra cosa es que el Alto Tribunal pudiera decidir salvar el obstáculo mediante una interpretación amplia de la ley, ello a la vista de la especial complejidad de la crisis y del alcance exclusivamente nocturno - y, por tanto, de menor repercusión en la vida de la generalidad de los ciudadanos- de la restricción horaria impuesta.

No queremos concluir sin aludir a otra cuestión básica de cara a evaluar la interpretación que durante este tiempo se ha hecho del artículo $116 \mathrm{CE}$ y que a fecha de hoy ${ }^{114}$ no ha sido resuelta por el Tribunal Constitucional. Nos referimos a la prórroga de seis meses decretada — RD 956/2020 — sobre ese tercer y último estado de alarma pues, aunque el artículo 116.2 CE no establece un plazo máximo

es inquietante para el futuro», citando, a continuación, los excesos cometidos por los Presidentes de Hungría, Honduras o Estados Unidos, durante la pandemia. Precisamente cuando, si en algo destaca el estado de excepción en España, es por reforzar el control que el Parlamento ejerce sobre el Gobierno.

111 También, en su caso, respecto de los cierres perimetrales establecidos, así como de los límites impuestos a las reuniones en el ámbito privado.

112 Entre otros, Díaz Revorio, F. J., «Suspensión de derechos y límites constitucionales del estado de alarma», en el Seminario Excepcionalidad y derecho: el estado de alarma a debate, organizado por la FMGA, celebrado el 21 de octubre de 2020; o Aragón Reyes, M., «Epílogo», op. cit., p. 14.

113 Del artículo 11 a) LOEAES se deduce que su aplicación supondrá la posibilidad general de circulación o permanencia durante ese tiempo, matizada por la aplicación de límites puntuales. En cambio, en el artículo 20.1 LOEAES, la regla general mientras opera la restricción es la prohibición de la circulación o permanencia, salvo contadas excepciones, como sucedió con los toques de queda: durante el horario nocturno establecido, la ciudadanía debía permanecer en casa, amén de ciertas salvedades.

114 Este trabajo se cierra a 16 de julio de 2021. 
de duración de la misma, existen argumentos de peso para afirmar la inconstitucionalidad de la prolongación decretada.

A estos efectos, conviene incidir en la labor de control de los poderes extraordinarios que el artículo 116 CE confiere al Congreso de los Diputados, hasta el punto de que el apartado quinto prohíbe su disolución durante la vigencia de cualquiera de los tres estados. Y, es que, amén del deber gubernamental de dación de cuentas a la Cámara Baja, esta asume un rol decisivo de codecisión periódica para la prórroga del estado de alarma, función constitucional que le es irrenuncia$\mathrm{ble}^{115}$. Por eso, resulta imperativo que la prórroga no alcance una duración tal que acabe imposibilitando el cumplimiento de tan importante tarea. Así las cosas, a falta de jurisprudencia constitucional al respecto, y partiendo siempre del carácter estrictamente indispensable y la proporcionalidad que han de revestir las medidas adoptadas — artículo 1.2 LOEAES — , lo razonable es que la prolongación no exceda el plazo máximo inicial de duración del estado de alarma, regla que se observa en el estado de excepción ${ }^{116}$. De esa forma, se logra un adecuado control al Gobierno por parte de un Congreso de los Diputados que podrá valorar con mucho más rigor la justificación o no de ciertas medidas a quince días vista. Por eso, lo adecuado desde un punto de vista constitucional habría sido proceder, como se hizo entre marzo y junio del año 2020, a la prolongación del estado de alarma cada quince días, en lugar de la interpretación exorbitada del texto constitucional llevada a cabo ${ }^{117}$.

\section{CONCLUSIONES}

Pese a los esfuerzos reguladores previos que puedan realizarse, la realidad nos demuestra la imposibilidad de prever todas y cada una de las situaciones de amenaza al orden constitucional susceptibles de producirse. Lo importante es tener en cuenta que, incluso en estos supuestos de auténtica excepcionalidad jurídica, y a fin de evitar abusos de poder, existen ciertos criterios jurídicos que siempre se deben respetar. Ello impide hablar de una desaparición o suspensión total del ordenamiento jurídico, incluso ante las emergencias más inverosímiles.

A nivel interno español, existen una serie de reglas, principios y valores inherentes al ordenamiento jurídico — por ejemplo, los de los artículos 1.1 y 9.3 $\mathrm{CE}$ - incluida la aplicación del juicio de la proporcionalidad en sus tres dimensiones: idoneidad, necesidad y proporcionalidad en sentido estricto - por ejemplo, la STC 64/2019, de 9 de mayo-. Y, desde un punto de vista internacional,

115 Aragón Reyes, M., «La prórroga del estado de alarma», El País, 28 de octubre de 2020.

116 Más al respecto, en Robledo, A., «El estado de alarma: donde quiere el gobernante», El País, 6 de noviembre de 2020.

117 En contra, por ejemplo, Presno Linera, M. A., en declaraciones a Eldiario.es, 26 de octubre de 2020 , para quien la prórroga de «uno o dos meses» le habría parecido «un plazo razonable». 
destacan, tanto las previsiones contenidas en la cláusula derogatoria del artículo $15 \mathrm{CEDH}$-incluido el reconocimiento del carácter absoluto de ciertos derechos fundamentales-, como los parámetros jurídicos fijados por la Comisión de Venecia — principios de legalidad, necesidad, proporcionalidad, etc.—, los cuales han sido igualmente asumidos por la Unión Europea.

En el intento de anticipar normativamente las distintas situaciones de emergencia constitucional que pudieran surgir, la Constitución española consagra unos estados de alarma, excepción y sitio —artículo 116 CE — cuyos supuestos de hecho, procedimiento para su declaración y medidas concretas han sido detallados en una LOEAES que, en algunos aspectos, convendría fuera modificada.

Justo a propósito de lo anterior, en la segunda parte del trabajo se analiza hasta qué punto, crisis susceptibles de ser abordadas a través del artículo $116 \mathrm{CE}$ y la LOEAES, acabaron derivando, por una razón u otra, en un desbordamiento del marco jurídico, a veces conforme a derecho y, en otras ocasiones, injustificado.

Un ejemplo de extralimitación normativa acorde a derecho lo encontramos en la respuesta regia llevada a cabo frente al golpe de Estado perpetrado el 23 de febrero de 1981. Con el Congreso de los Diputados tomado por los militares, la imposibilidad de declarar el estado de sitio —artículo 116.4 CE— acabó justificando, entre otras cosas, la asunción de poderes militares efectivos por quien ostenta el mando supremo de las Fuerzas Armadas a título meramente honorífico - artículo $62 \mathrm{~h}$ ) CE- Estamos pues, ante un caso perfectamente ilustrativo de lo que para nosotros es el auténtico derecho constitucional de excepción, aplicado a las situaciones de emergencia constitucional reglada o insuficientemente reglada.

En cambio, la extralimitación gubernamental producida frente a la crisis de los controladores aéreos, entre finales del año 2010 y comienzos del 2011, constituye un ejemplo de actuación contraria a derecho, ello desde el momento en que se abordó a través del estado de alarma del artículo 116.2 CE — RD 1673/2010-. $\mathrm{Y}$, es que, partiendo de que la paralización de los servicios públicos esenciales para la comunidad, sin ninguna circunstancia adicional, constituye un supuesto propio del estado de excepción —artículos 13.1 LOEAES y $116.3 \mathrm{CE}$-, el debate sobre la imperativa necesidad de someter a los controladores al fuero militar —algo solo permitido en el estado de sitio ex artículo 117.5 CE— deviene del todo secundario.

El ejemplo más reciente y grave de respuesta inadecuada ante una emergencia constitucional reglada o insuficientemente reglada lo encontramos en el marco de la pandemia por COVID-19. Especialmente, por imponer un confinamiento general casi total - RD 463/2020- bajo un estado de alarma que, como el artículo 55.1 CE establece, no tiene capacidad para imponer suspensiones generales en materia de derechos fundamentales. Debería haberse declarado el estado de excepción, extremo confirmado por el Tribunal Constitucional, que concede una importancia central a la obligatoriedad del permiso parlamentario previo a la adopción de medidas de semejante calado — STC 148/2021, de 14 de julio, FFJJ 
5 y 11 - Como igualmente importante será lo que el Alto Tribunal tenga que decir, entre otras cosas, respecto de la prórroga única de seis meses acordada —RD 956/2020 — sobre el último estado de alarma — RD 926/2020, de 25 de octubre- Una prolongación que, salvo mejor opinión en contrario, resulta abiertamente inconstitucional dado que imposibilita el adecuado control parlamentario que la aplicación del artículo 116 CE exige.

\section{$* * *$}

TITLE: Unregulated or Insufficiently Regulated Constitutional Emergencies: A Theoretical and Practical Approach

ABstract: Together with the usual legal disputes, dealt with through the standard legal instruments, certain situations sometimes arise which threaten the continuity of the constitutional order and require the application of extraordinary measures. These are scenarios that imply a greater concentration of power but still require respect for certain basic legal premises in order to prevent authoritarian behaviours. Since non-regulated or insufficiently regulated emergencies are the most extreme example of this, in the first part of the paper we will see that, even in these cases of true exception, there are sufficient legal criteria to confront danger with guarantees. We will then look at the way in which Spanish public authorities have applied such parameters with clearly positive outcomes and others that have been rather controversial. Crucial in the latter respect is the recent decision of the Spanish Constitutional Court, which has rightly established the partial unconstitutionality of Royal Decree 463/2020, of 14 March, declaring a state of alarm against COVID-19. Because a fundamental rights suspension cannot be accepted under this figure, a state of emergency should have been activated, as it requires parliamentary permission prior to the adoption of such measures.

RESUMEN: Junto con las babituales controversias jurídicas, abordadas desde el derecho de la normalidad, surgen a veces ciertas situaciones que, amenazando la propia subsistencia del orden constitucional, requieren la aplicación de medidas extraordinarias. Son supuestos que implican una mayor acumulación de poder pero que siguen exigiendo el respeto a determinadas premisas jurídicas básicas, ello con el fin de prevenir conductas autoritarias. Siendo las emergencias no regladas o insuficientemente regladas el ejemplo más extremo de ello, en la primera parte del trabajo comprobaremos como, hasta en esos supuestos de auténtica excepción, existen criterios jurídicos suficientes para afrontar el peligro con garantías. Acto seguido, veremos ya la manera en que los poderes públicos han aplicado esos parámetros en España, con experiencias netamente positivas y otras que no lo han sido tanto. Crucial resulta, a este último respecto, la reciente STC 148/2021, de 14 de julio, estableciendo la inconstitucionalidad parcial del RD 463/2020, de 14 de marzo, de declaración del estado de alarma contra la COVID-19. Porque, no cabiendo la suspensión de derechos fundamentales bajo dicha figura, debería baberse recurrido al estado de excepción, en cuanto que instrumento que exige el permiso parlamentario previo a la adopción de semejantes medidas.

KEY WORDS: state of exception, state of alarm, state of emergency, state of siege.

Palabras Clave: derecho de excepción, estado de alarma, estado de excepción, estado de sitio.

FECHA DE RECEPCIÓN: 07.07.2021

FECHA DE ACEPTACIÓN: 20.09.2021 